\title{
Structure, in vivo detection and anti-bacterial activity of metabolites of SQ109, an anti-infective drug candidate
}

Satish R. Malwal*1, Matthew D. Zimmerman, ${ }^{2}$ Nadine Alvarez, ${ }^{2}$ Jansy P. Sarathy ${ }^{2}$, Véronique Dartois, ${ }^{2,3}$ Carol A. Nacy ${ }^{4}$ and Eric Oldfield*1

${ }^{1}$ Department of Chemistry, University of Illinois at Urbana-Champaign, Urbana, IL 61801, United States

${ }^{2}$ Center for Discovery and Innovation, 111 Ideation Way, Nutley, NJ 07110, United States

${ }^{3}$ Hackensack School of Medicine, Department of Medical Sciences, 123, Metro Boulevard, Nutley, NJ 07110, United States

${ }^{4}$ Sequella, Inc., 9610 Medical Center Drive, Suite 200, Rockville, MD 20850, United States

\begin{abstract}
SQ109 is a drug candidate for the treatment of tuberculosis (TB). It is thought to target primarily the protein MmpL3 in Mycobacterium tuberculosis, but it also inhibits the growth of some other bacteria, as well as fungi and protozoa. SQ109 is metabolized by the liver, and it has been proposed that some of its metabolites might be responsible for its activity against TB. Here, we synthesized six potential P450 metabolites of SQ109 and used these as well as 10 other likely metabolites as standards in a mass spectrometry study of M. tuberculosis-infected rabbits treated with SQ109, in addition to testing all 16 putative metabolites for anti-bacterial activity. We found that there were just two major metabolites in lung tissue: a hydroxy-adamantyl analog of SQ109 and N'-adamantylethylenediamine. Neither of these, or the other potential metabolites tested, inhibited the growth of $M$. tuberculosis, or of $M$. smegmatis, Bacillus subtilis or E. coli, making it unlikely that an SQ109 metabolite contributes to its anti-bacterial activity. In the rabbit TB model, it is thus the gradual accumulation of non-metabolized SQ109 in tissues to therapeutic levels that leads to good efficacy. Our results also provide new insights into how SQ109 binds to its target MmpL3, based on our mass spectroscopy results which indicate that the charge in SQ109 is primarily localized on the geranyl nitrogen, explaining the very short distance to a key Asp found in the X-ray structure of SQ109 bound to MmpL3. Our results also suggest that it is intact SQ109 that is likely to target some of the other bacteria, fungi and protozoa in which MmpL3-like proteins have recently been reported.
\end{abstract}




\section{Introduction}

According to the World Health Organization, an estimated 10 million people fell ill with tuberculosis (TB) in 2019 and there were an estimated 1.2 million TB deaths among HIV-negative people and an additional 208,000 deaths among HIV-positive people ${ }^{1}$. TB is caused by the bacterium Mycobacterium tuberculosis and is very difficult to treat ${ }^{2}$, requiring use of multiple antibiotics for many months, and the occurrence of drug resistance is of concern. There is thus a need for the development of new antibiotics having novel mechanisms of action in order to target, in particular, drug-resistant bacteria. One such compound is SQ109 (1, Figure 1) ${ }^{3,4}$. SQ109 is an ethylenediamine that contains an N-geranyl as well as an N'-2-adamantyl group and was discovered in a combinatorial chemistry and highthroughput screening program in which 63,238 analogs of the early TB drug ethambutol were synthesized $^{3,4}$. The major target of SQ109 in M. tuberculosis is thought ${ }^{5}$ to be the protein MmpL3, mycobacterial membrane protein Large 3, a transporter of trehalose monomycolate ${ }^{5}$. The structure of MmpL3 (from M. smegmatis) with and without SQ109 was recently been reported ${ }^{6,7}$. In addition to targeting MmpL3, SQ109 can inhibit the enzyme MenA (isoprenyl diphosphate:1,4-dihydroxy-2naphthoate isoprenyltransferase) involved in menaquinone biosynthesis ${ }^{8}$, and can act as a protonophore uncoupler, ${ }^{8,9}$ as do some other compounds that inhibit MmpL3 ${ }^{10}$. SQ109 also inhibits the growth of other bacteria, e.g. Clostridium difficile and Helicobacter pylori ${ }^{4}$; the fungi Candida albicans and Aspergillus fumigatus ${ }^{4}$, as well as the protozoan parasites Trypanosoma cruzi ${ }^{11}, T$. brucei $^{12}$, Leishmania donovani ${ }^{13}$, L. mexicana ${ }^{14}$ and Plasmodium falciparum ${ }^{8}$, activity consistent with the polypharmacology of SQ109 and, perhaps, of one or more of its metabolites.

SQ109 is metabolized in rats, mice and $\operatorname{dogs}{ }^{15,16}$ with $\left[{ }^{14} \mathrm{C}-\mathrm{SQ} 109\right]$ half-life values of $5 \mathrm{hrs}$ in mice ${ }^{15}$ and $>5$ hrs in rats and dogs ${ }^{16}$ and is metabolized, as determined by liquid chromatography-mass spectrometry (LC-MS), by rat and human liver microsomal preparations ${ }^{16}$ to compounds having reported masses $\left(\mathrm{MH}^{+}\right)$in electrospray ionization (ESI) mass spectrometry of $\mathrm{m} / \mathrm{z}=195,347,361$ and 363. Metabolism of SQ109 is expected to occur via cytochromes P450 and to test this, Jia et al. ${ }^{16}$ investigated the reactions of SQ109 in microsomes prepared from insect cells transfected with cDNAs encoding human CYP1A2, CYP2A6, CYP3A4, CYP2B6, CYP2C8, CYP2C9, CYP2C19 and CYP2D6. There was extensive metabolism with the CYP2C19 system, forming metabolites with $\mathrm{m} / \mathrm{z}$ of 195, 347, 361 and 363, and with the CYP2D6 cDNA transfected cells, primarily the $\mathrm{m} / \mathrm{z}=361$ and 363 species formed. There were no significant metabolite peaks at these masses with CYP2A6, 
CYP2C8 or CYP2C9, and only negligible amounts of $\mathrm{m} / \mathrm{z}=347$ with the CYP1A2, CYP3A4 and CYP2B6 systems. Given that the molar masses obtained correspond to the molar masses of SQ109 $\left(\mathrm{m} / \mathrm{z}=331\right.$ for the $\mathrm{MH}^{+}$form) with 1 oxygen $(\mathrm{m} / \mathrm{z}=347)$ or two oxygens $(\mathrm{m} / \mathrm{z}=363)$, Jia et al. proposed formation of a variety of adamantanol (2), epoxide (3), hydroxylamine (4) and ketone

a)<smiles>CC(C)=CCCC(C)=CCNCCNC1C2CC3CC(C2)CC1C3</smiles>

1, SQ109<smiles>CC(C)=CCCC(C)=CCN(O)CCNC1C2CC3CC1C3C2</smiles>

4<smiles>CC(C)=CCCC(C)=CCNCCNC1C2CC3CC1C3C2</smiles>

2<smiles>CC(C)=CCCC(C)C(=O)NCCNC1C2CC3CC(C2)CC1C3</smiles>

5<smiles>CC(C)=CCCC(C)OCCNCCNC1C2CC3CC(C2)C1C3</smiles>

3<smiles>CC(C)=CCCC(C)C(=O)NCCNC1C2CC3CC(C2O)C1C3</smiles>

6

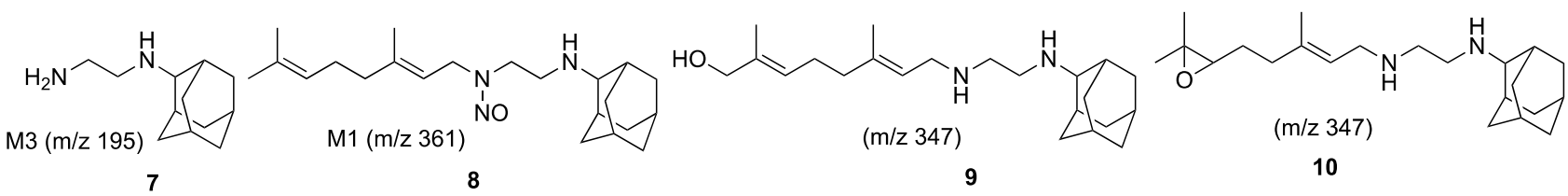

b)

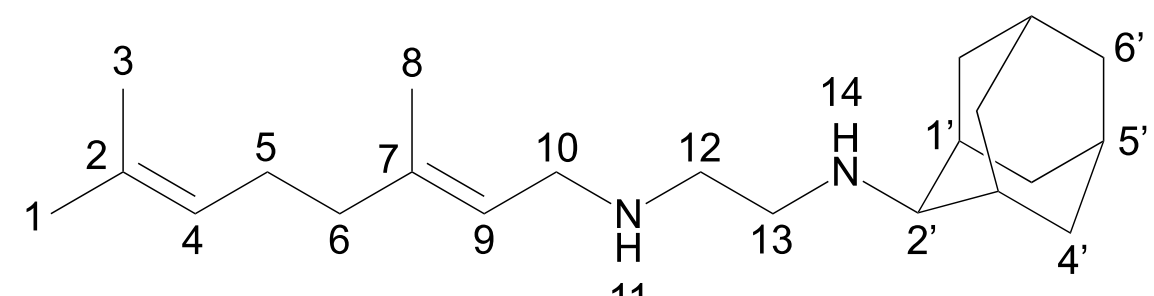

11

c)

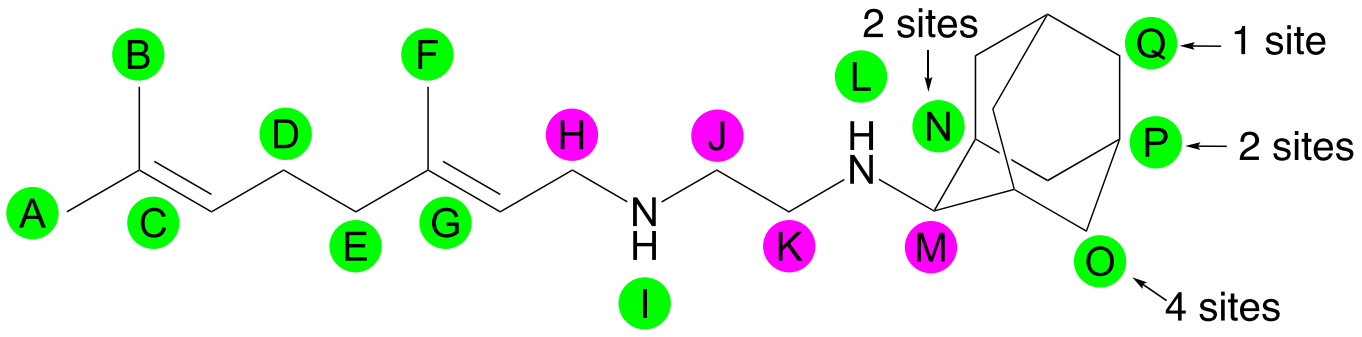

Figure 1. Structure of SQ109 together with metabolites proposed by Jia et al. ${ }^{16}$, numbering system used in the Text and P450 oxygenation sites. (a) SQ109 (1) and metabolites proposed previously ${ }^{16}$. (b) Numbering system used for SQ109 and its analogs. Different computer programs may use different numbering systems and the IUPAC numbering can vary with different substitutions. (c) The 17 sites (A-Q) that are potential sites for P450 oxygenation. The green colored sites can form stable alcohols (A, B, D, E, F in the geranyl group, N, O, P and Q in the adamantane). The pink colored sites are expected to result in chemically unstable amino-alcohols (H, J, K, M); $2^{\circ}$ hydroxylamines (I, L) are expected in cells to be further oxidized to nitrones then cleaved to oximes, as discussed in the Text. 
$(\mathbf{5 , 6 )}$ products; the formation of $\mathrm{N}$-2-adamantylethylenediamine $(7, \mathrm{~m} / \mathrm{z}=195)$, as well as the formation of an N-nitroso SQ109 adduct $(8, \mathrm{~m} / \mathrm{z}=361)$, though they also noted the need for further investigations using authentic metabolites ${ }^{16}$.

What was particularly interesting about the Jia et al. results was the very rapid metabolism of SQ109 in vitro, with e.g. only $0.8 \%$ of SQ109 remaining after a 30-minute incubation with CYP2D6, or 45\% remaining after a 30-minute incubation with CYP2C19. The $\left[{ }^{14} \mathrm{C}-\mathrm{SQ} 109\right]$ half-life, liver microsome and P450 results are consistent with the idea that it is likely to take several days or weeks for SQ109 to accumulate to therapeutic levels in patients. Moreover, it has been suggested ${ }^{17}$ that SQ109 metabolites might be active species, as with the metabolites of other TB drugs such as isoniazid ${ }^{18}$ and pyrazinamide $^{19}$. The question then arises as to what the structures of the SQ109 metabolites formed in vivo are, and do they have antibacterial activity.

There are many possible sites in SQ109 that might be oxygenated by human cytochromes P450 (of which there are $57^{20}$ ), plus, there are 20 M. tuberculosis $\mathrm{P} 450 \mathrm{~s}^{21}$, some of which might also oxygenate SQ109. Indeed, a very recent paper ${ }^{22}$ showed that the M. tuberculosis cytochrome P450, CYP124, can oxidize SQ109. The authors determined the structure of MtCYP124 with SQ109 bound ${ }^{22}$, finding that the carbon in the trans- or $E$ - terminal methyl group in SQ109 (i.e. in the $\mathrm{Me}_{2} \mathrm{C}=\mathrm{CH}-\mathrm{CH}_{2}$ - fragment) was only $\sim 4 \AA$ from the heme iron; the distance from the putative iron(IV) oxide oxygen to the $\mathrm{H}^{\bullet}$ to be abstracted presumably being much shorter. Their observation led to the idea that a terminal methyl in SQ109 was oxygenated to the $\mathrm{CH}_{2} \mathrm{OH}$-containing species $\mathbf{9}$, a compound that was proposed to bind to Thr or Ser $\mathrm{OH}$ groups in MmpL3-something that might enhance activity. There is extensive evidence for the hydroxylation of terminal methyl groups in isoprenoids by MtCYP12423, including compounds such as farnesol and geranylgeraniol, supporting the proposed structure. However, in humans, the enzyme with the closest sequence similarity to MtCYP124, obtained from a BLAST search (Supporting Information Figure S1), is CYP2J2, which can have epoxidase activity, ${ }^{24}$ which would again result in $\mathrm{m} / \mathrm{z}=347$ but this time, from an epoxide. In addition, some P450 cytochromes can directly convert olefins to ketones via a 1,2-shift, which could again result in formation of $\mathrm{m} / \mathrm{z}$ $=347 . .^{25}$

Here, we first investigated computationally the likely sites targeted by P450 enzymes and we synthesized seven stable analogs of SQ109 containing a single oxygen, corresponding to m/z= 347 . We then used these compounds together with ten other possible metabolites (arising from reactive 
intermediates) as standards in a mass spectrometric investigation of SQ109 metabolites in the lungs of M. tuberculosis-infected rabbits. In addition, we tested all compounds for antibacterial activity using M. tuberculosis, M. smegmatis, Bacillus subtilis and Escherichia coli, organisms that are inhibited by $\mathrm{SQ} 109^{8}$, suggesting reasons for the activity or lack thereof, of the various species investigated.

\section{Results and Discussion}

Computational predictions. There are many possible reactions of SQ109 with cytochromes P450, due to the presence of highly reactive allylic (in the geranyl group) and tertiary carbon sites (in the adamantyl group), as well as the presence of two secondary amine groups (in the ethylenediamine fragment). Cytochrome P450 oxidations involve radical reactions and the general reactivity order for $\mathrm{H}^{\bullet}$ abstraction from a C-H group of relevance here is: allyl $\mathrm{l}^{26}>3^{\circ}>2^{\circ}$. Allyl group $\mathrm{H}^{\bullet}$ abstraction is favored since allyl radicals are stabilized by resonance/delocalization, while the other free radicals are stabilized due to electron donation from neighboring groups, leading to the stability sequence noted above. Adjacent atoms, in particular $\mathrm{N}$ and $\mathrm{O}$, can greatly stabilize radicals due to donation of electron density from $\mathrm{N}$ or O lone pairs, so we would expect — at least qualitatively — that in SQ109, the allylic $\mathrm{CH}_{2}$ adjacent to the ethylenediamine $\mathrm{N}$ would be most readily oxidized. The other allylic groups as well as the tertiary $\mathrm{CH}$ groups in the adamantane fragment would also be susceptible to oxygenation. Moreover, the terminal, allylic $\mathrm{CH}_{2} \mathrm{OH}$ group could be further oxidized to a carboxylic acid (via the aldehyde and aldehyde diol), as found e.g. in the metabolism of imrecoxib in humans ${ }^{27}$, leading to an unique $[+2 \mathrm{O}-2 \mathrm{H}]$ species having $\mathrm{m} / \mathrm{z}=361$. This brief discussion applies primarily to radical reactivity in the absence of a protein environment, so to help better determine which compounds might be most likely to form due to mammalian CYP450 action — to guide our synthesis and testing program — we used three computer programs ${ }^{28-30}$ that utilize known P450 reactivity data, to suggest the most likely positions for oxidations that would help explain formation of the stable $\mathrm{m} / \mathrm{z}=195,347(+10) ; 361$ $(+2 \mathrm{O}-2 \mathrm{H}) ; 363(+2 \mathrm{O}) ; 377(+3 \mathrm{O}-2 \mathrm{H}) ; 377[+3 \mathrm{O}-2 \mathrm{H}]$ and $379[+3 \mathrm{O}]$ ions we see experimentally. The predictions also suggest which compounds would form and then decompose to other metabolites, with both stable SQ109 metabolites as well as SQ109 breakdown-products potentially having activity in cells. 
Since the atom numbering systems used by different computer programs (e.g. for P450 metabolism, for NMR peak assignments and even for IUPAC naming) may differ, to facilitate discussion we adopt here the numbering system for SQ109 analogs shown in Figure 1b. With the exception of the nitrogen attached to the adamantane, the atoms in the geranyl and ethylenediamine groups do not use primes, while the adamantylamines do (e.g. 5'-OH). There are 17 nonequivalent $\mathrm{C}$ or $\mathrm{N}$ sites in SQ109 that might be oxygenated by P450s: six allylic; two olefinic; two secondary amines; two ethylenediamine carbons; and five adamantanes. We designate these 17 sites as A-Q, as shown in Figure 1c. Chemically equivalent atoms in the adamantyl group are not indicated since their oxygenation would result in the same product (e.g. C1' and C3' are equivalent).

The GLORY/FAME 2 program $^{28}$ predicted oxidation at the terminal methyl groups (with equal probabilities), Supporting Information Figure S2a, together with the allylic $\mathrm{CH}_{2}$ adjacent to the geranylamine $\mathrm{NH}$ group. Using the Xenosite server ${ }^{29}$, both stable as well as unstable oxygenation was predicted at the terminal double bond, Supporting Information Figure S2b, together with strong but unstable oxygenation at both $\mathrm{CH}_{2}$ groups adjacent the geranylamine $\mathrm{NH}$ group. In both of these sets of predictions, these are global results and are based on a diverse set of CYP450s. The third program was the SMART CYPs program ${ }^{30}$ in which specific predictions for 3 CYPs were made: for 3A4, 2D6 and for $2 \mathrm{C} 9$. For $3 \mathrm{~A} 4$, the top ranked positions were the four carbons attached to the two nitrogens, however, there was little to no activity of SQ109 with 3A4 seen experimentally, ruling out these positions as likely sites of oxidation with $3 \mathrm{~A} 4$ - though suggestive perhaps of their oxidation with other P450s. However, with 2D6, Supporting Information Figure 2c, the top 3 sites are predicted to be the two terminal Me groups together with the adamantyl group at the unique methylene site C6', followed by the two adjacent $3^{\circ}$ sites. Oxygenation of both the terminal Me as well as the adamantane would be of interest since it would lead to $\mathrm{m} / \mathrm{z}=363(+2 \mathrm{O})$ species seen with $2 \mathrm{D} 6$. Moreover, when we used 1-OH SQ109 (9) as the target, the terminal methyl-oxidized group, the SMART CYPs program results indicated further oxygenation at the $1-\mathrm{OH}$ position to the aldehyde as well as oxidation of the aldehyde, which would result in formation of a terminal carboxylic acid with $\mathrm{m} / \mathrm{z}=361$ (+2O$2 \mathrm{H})$, as well as, potentially, to a series of $\mathrm{m} / \mathrm{z}=377(+3 \mathrm{O}-2 \mathrm{H})$ species, due to Me as well as adamantane oxygenations. 
Synthesis of stable SQ109 oxygenated analogs and selection of other potential metabolites. The computational and other results described above help guide the synthesis of the most likely, chemically stable SQ109 metabolites, such as 9, as well help predict unstable

a)

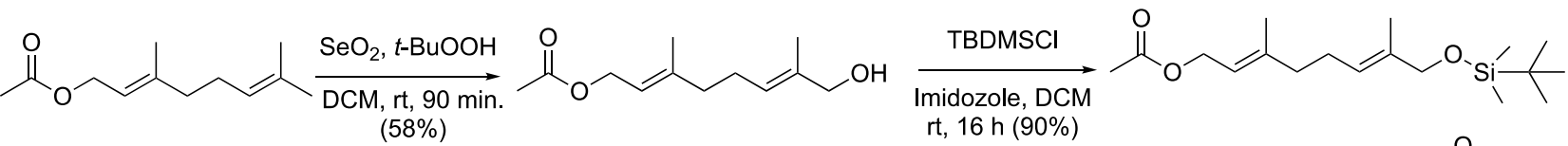
$(58 \%)$ rt, $16 \mathrm{~h}(90 \%)$
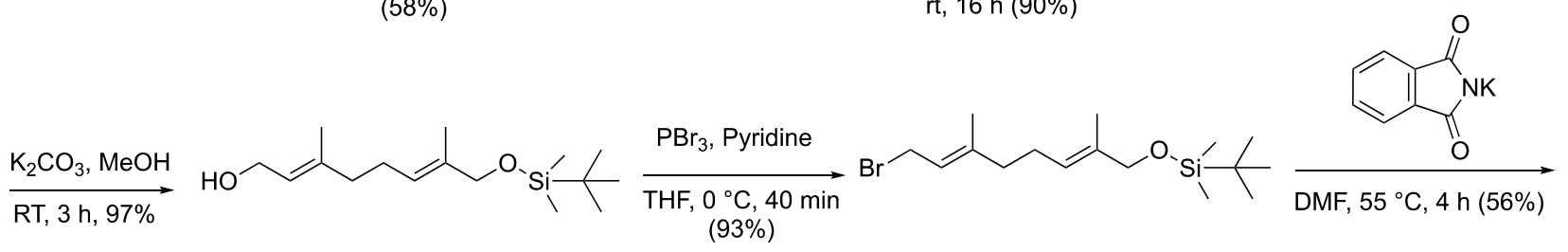<smiles>CO[R9]([13CH3])([13CH3])[13CH2]N</smiles><smiles>CC(=CCN)CCC=C(C)CO[Si](C)(C)C(C)(C)C</smiles>

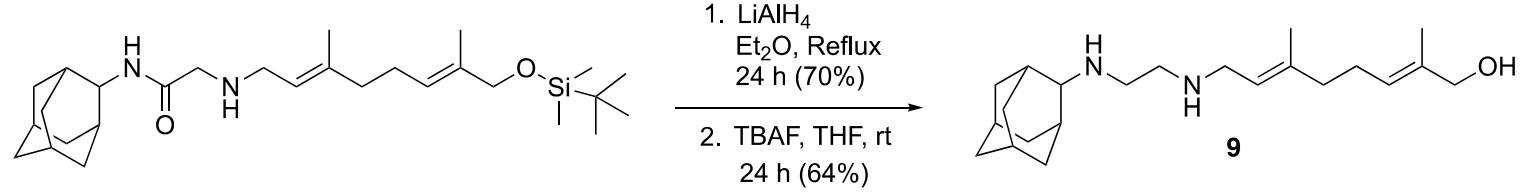

b)<smiles>CC(C)=CCCC(C)=CCNCCNC1C2CC3CC(C3)C21</smiles><smiles>CC(C)=CCCC1(C)OC1CNCCNC1C2CC3CC(C3)C1C2</smiles><smiles>CC(C)C(=O)CC/C=C/CNCCNC1CC2C3CC(C3)CC12</smiles>

c)

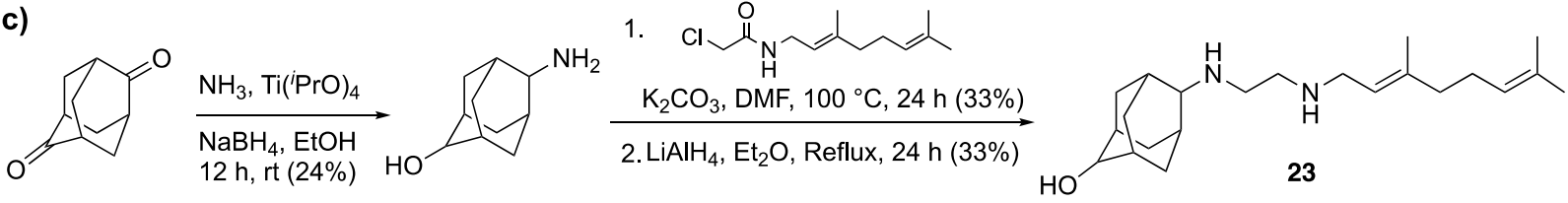

d)

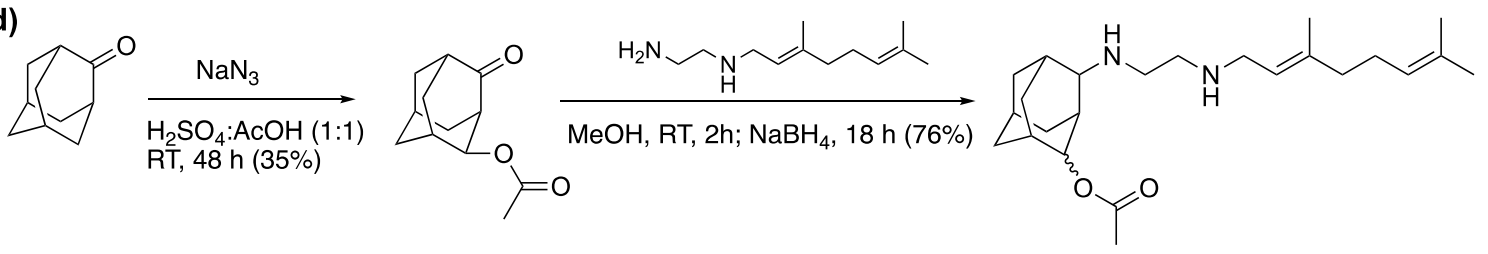

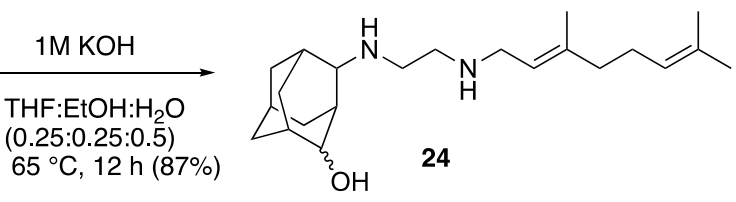


Figure 2. Synthetic schemes for SQ109 analogs. a) The terminal Me 1-OH analog 9. b) The central epoxide 3 and other $m$-CPBA oxidation products. c) The unique C6'-OH 23. d) The 4'-OH product 24. Note that there are 4 equivalent sites and that both axial and equatorial isomers are formed.

species that might lead to other, possibly active, metabolites. As noted above, there are a total of 17 nonequivalent sites in SQ109, shown in Figure 1c, that might be oxygenated by P450 cytochromes. Sites that are expected to be oxygenated to chemically (as opposed to metabolically) stable [+1O] species are shown in green in Figure 1c, those that are expected to lead to chemically unstable species (amino-alcohols) are shown in pink.

In the geranyl group, there are 5 allylic sites (A, B, D, E and F) that might be oxygenated, forming chemically stable alcohols, as well as two olefinic sites ( $\mathrm{C}$ and $\mathrm{G})$, that can form chemically stable epoxides. The allylic methylenes (D, E) were not predicted to be oxidized by any of the computer programs and neither was the C-8 Me (site F), so were not chosen for synthesis. Both terminal Me groups were predicted to be oxygenated, but since several isoprenoids are oxygenated only at C1 (site A) and not at C-3 (site B), we chose to synthesize the trans-Me species, the one proposed to be formed by MtCYP124. The synthesis route is shown in Figure 3a and full synthesis and characterization details are given in the Methods Section and in the Supporting Information. As discussed more below, further oxygenation at this site could also lead via the aldehyde to the acid, consistent with the observation of the single $[+2 \mathrm{O}-2 \mathrm{H}] \mathrm{m} / \mathrm{z}=361$ species seen experimentally. Site $\mathrm{C}$ was predicted by the Xenosite program to be both stably as well as unstably oxygenated, Supporting Information Figure 2b. Stable oxygenation represents epoxidation of the terminal 2,4 double bond to form $\mathbf{1 0}$ (Figure 1a), so we used a $m$-chloroperbenzoic acid (mCPBA) route to attempt synthesis of this terminal $(2,3)$ epoxide, Figure 3b. We were unable to isolate any $\mathbf{1 0}$; however, we did obtain evidence for the formation of the central 7,9-epoxide 3 as well as the terminal $(\mathrm{C} 2,4)$ diol 11 and the C-4 ketone 12. The latter was obtained in 95\% purity (by qNMR) although 3, 11 and 12 were impure $(86 \%, 60 \%, 86 \%$, respectively), but their presence does suggest that formation of the ketone $\mathbf{1 2}$ occurs via an epoxide>diol>ketone route, Supporting Information Figure S3a, via a hydride 1,2-shift - essentially the pinacol/pinacolone rearrangement that has previously been shown to occur in some m-CPBA oxidations of olefins, ${ }^{31}$ in particular under acidic conditions ${ }^{32,33}$. Although the ketone $\mathbf{1 2}$ was not specifically predicted computationally, it would be in the category of an unstable oxygenation product of a P450 and was 
investigated further below for possible activity in several bacteria, and its presence as a metabolite in M. tuberculosis infected rabbits. As noted above, P450 cytochromes can directly convert olefins to ketones via a 1,2-shift mechanism, Supporting Information Figure S3b, and need not employ the epoxide>diol>ketone route discussed above. Site $\mathrm{H}$ is the allylic $\mathrm{CH}_{2}$ next to $\mathrm{N}$, expected to be highly reactive - an allyl radical stabilized by resonance and the $\mathrm{N}$ lone pair. Oxidation at $\mathrm{C} 10$ (Figure $1 \mathrm{~b}$ ) is expected to result in formation of an unstable amino-alcohol species (Figure 3a) that disproportionates into the $\mathrm{N}$-adamantylethylenediamine proposed ${ }^{16}$ before $(\mathbf{7}$, the $\mathrm{m} / \mathrm{z}=195$ species), geranial (13) and most likely in cells, to geranic acid $\mathbf{1 4}$, since aldehydes are unlikely to be stable inside cells. Potential metabolites (such as 7, 13 and 14) that were tested for anti-bacterial acidity are shown shaded in pink in Figure 3.

In the ethylenediamine fragment, all four sites (I, J, K and L) are predicted to be oxygenated by P450s. The two $2^{\circ}$ amine groups (sites I and L) are expected to form $2^{\circ}$ hydroxylamines ${ }^{34}$. Such compounds are chemically stable species though in vivo are expected ${ }^{34}$ to be further oxidized to nitrones and thence to amines and the geranial oxime (15a) or 2-adamantanone oxime (16), as shown in Figures 3b,c. We found that a commercial sample of $\mathbf{1 5 a}$ was actually the 2-isoxazoline $\mathbf{1 5} \mathbf{b}$, which appears to form during synthesis by cyclization of 15a, as shown in Supporting Information Figure $\mathrm{S} 4 \mathrm{a}$, so both were investigated as possible metabolites. The two isomeric species shown in Figures $3 \mathrm{~d}$ and $3 \mathrm{e}$ would be $[+\mathrm{O}-2 \mathrm{H}]$ species with $\mathrm{m} / \mathrm{z}=345$, and these were not seen experimentally. Three different attempts at the synthesis of the secondary hydroxylamines are shown in Supporting Information Figure S5, but were not successful. Sites J and K (the methylene groups in the ethylenediamine moiety) were both predicted to be reactive and would be oxidized to unstable aminoalcohols, so their synthesis was not attempted, but they could form in animals, leading (Figures 3f,g) to geranylamine (17) and 2-aminoadamantane (18), both of which were used as MS standards and tested for anti-bacterial activity.

In the amino-adamantyl group, there are 5 nonequivalent sites that can be oxygenated: $\mathrm{M}, \mathrm{N}, \mathrm{O}, \mathrm{P}$ and Q. Site $\mathrm{M}$ is the adamantane $\mathrm{C} 2$ ' that is bonded to the ethylenediamine $\mathrm{N}$ ' and its oxygenation 
a)

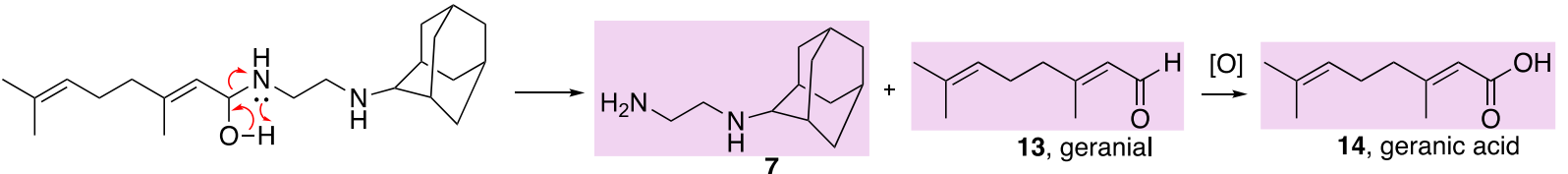

b)

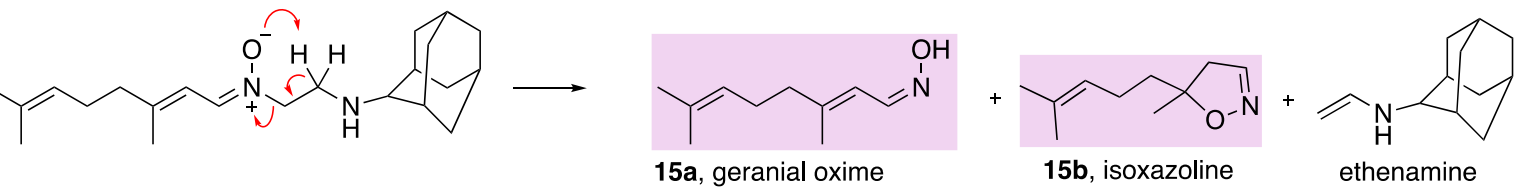

c)

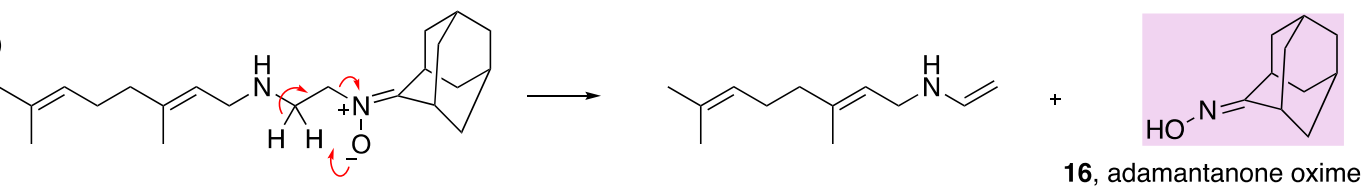

d)

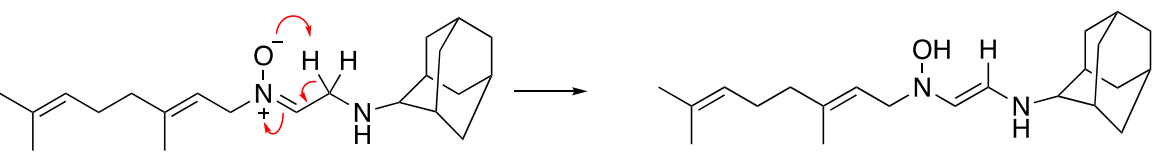

e)

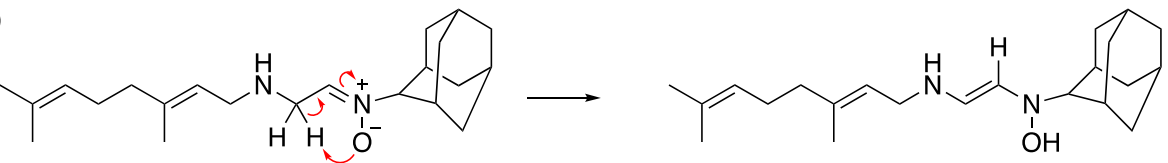

f)<smiles>CC(C)=CCC/C(C)=C/CNC(=O)NCC1C2CC3CC(C2)CC1C3</smiles><smiles>CC(C)=CCC/C(C)=C/CNC(O)(CNC1C2C=CC3CC(C2)CC1C3)CNC1C2CC3CC(C2)CC1C3</smiles>

g)

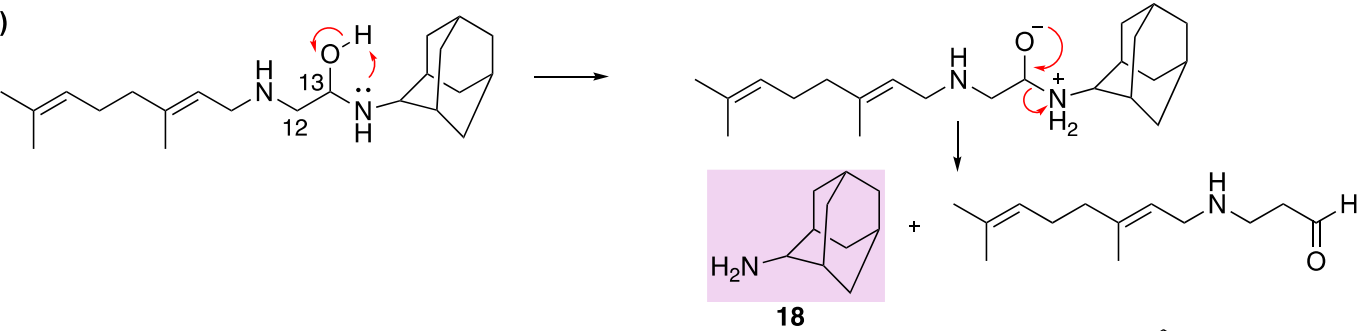

h)

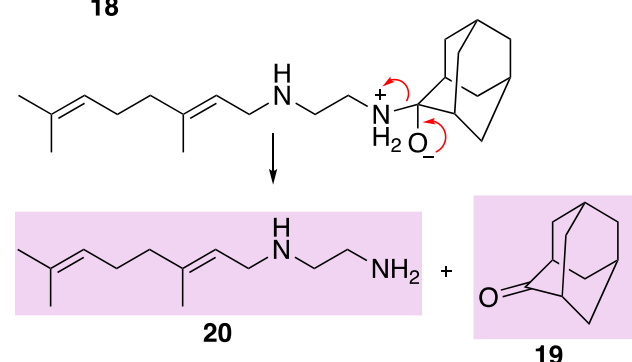

Figure 3. Formation of unstable oxygenated species and their decomposition. a) Oxygenation at C10 results in formation of an unstable aminoalcohol that decomposes to the amine $\mathbf{7}$ and the aldehyde $\mathbf{1 3}$. The mechanism could be concerted or sequential. Aldehydes are not very stable in cells and can hydrate to gem-diols that are then oxidized to acids. b) The $2^{\circ}$ amine SQ109 is oxygenated at the geranyl nitrogen to the $2^{\circ}$ hydroxylamine which is then is oxidized to the nitrone that then forms the 
oxime 15a and an amine. It appears that, at least in cells, the oxime 15a can then cyclize to form the 2-isoxazoline 15b. c) As b) but oxygenation at the adamantyl nitrogen site leading to formation of $\mathbf{1 6}$. d) and e) Alternate nitrones that might form unsaturated hydroxylamines but there are no corresponding $[+\mathrm{O}-2 \mathrm{H}] \mathrm{m} / \mathrm{z}=345$ ions seen experimentally. f) Oxygenation at $\mathrm{C} 12$ leads to geranylamine 17. g) Oxygenation at C13 leads to 2-aminoadamantane 18. h) Oxygenation at C2' leads to 2-adamantanone 19 and geranylethylenediamine 20. Pink=tested in bacteria.

would result in formation of an unstable amino-alcohol, expected to disproportionate into 2adamantanone 19 and N-geranylethylenediamine, 20, Figure 3h. The 4 other sites would each produce stable adamantanols: site $\mathrm{N}$, the $\mathrm{C} 1$ ' site (and its equivalent $\mathrm{C} 3$ ' site); site $\mathrm{O}$, the $\mathrm{C} 4$ ' site (and its 3 other equivalent sites); site $\mathrm{P}$, the C5' site (and its other equivalent site) and site $\mathrm{Q}$, the unique C6' site, shown for clarity below. All of these are chemically stable species (though some might be further oxidized in vivo) and we synthesized all four: C1' (21), C5' (22), C6' (23) and C4' (24), as shown in Figures 2c,d and the Methods Section and Supporting Information.<smiles>CC(C)=CCC/C(C)=C/CNCCNC1C2CC3CC(C2)C(C)(O)C1(O)C3</smiles><smiles>CC(C)=CCC/C(C)=C/CNCCNC1C2CC3CC1CC(C2)C3C(C)O</smiles>

We elected to synthesize all four stable adamantanol analogs (not just the C6' site predicted by using the SMART CYPs program) since $3^{\circ}$ carbons are expected to be more reactive than the unique $2^{\circ}$ site predicted, plus, the activities of the C1'-OH and C5'-OH SQ109 analogs have been reported ${ }^{35}$, the $\mathrm{C} 1$ '-OH compound having the same activity as did SQ109 against M. tuberculosis ${ }^{35}$. If the C1'-OH were a major metabolite, that would be of particular interest since it has high activity. The synthetic route to the C4' $-\mathrm{OH}$ analog of SQ109 is shown in Figure 2d and involved reductive animation of 4acetoxy-2-adamantanone ${ }^{36}$ with $\mathrm{N}$-geranylethylenediamine followed by $\mathrm{KOH}$-mediated acetoxy 
deprotection to give a $\sim$ 0.52:1 mixture of axial and equatorial isomers (as determined by ${ }^{1} \mathrm{H} N M R$ ), $\mathbf{2 4 a}$ and $\mathbf{2 4 b}$. These were not separated and are simply designated as $\mathbf{2 4}$ in what follows.

Quantitation of SQ109 and its metabolites in the lungs of M.tuberculosis infected rabbits. Next, we investigated the nature of the metabolites found in rabbits that had received 7 oral daily doses of SQ109 at the human-equivalent dose of $25 \mathrm{mg} / \mathrm{kg}$. A representative set of LC-MS results for lung extracts from one rabbit is shown in Figure 4. Results for a second rabbit were very similar. The most abundant species has $\mathrm{m} / \mathrm{z}=331$ and based on exact mass, retention time and fragmentation pattern, corresponds to SQ109 $[\mathrm{MH}]^{+}$. The most abundant SQ109 metabolites have m/z=197, corresponding to 7 , and a series of compounds having $\mathrm{m} / \mathrm{z}=347$, corresponding to SQ109 [+1O]. The next most abundant species are di- and tri-oxygenated SQ109s, having total integrated peak intensities of $~ 8 \%$ [+2O] and $\sim 1 \%[+3 \mathrm{O}]$ of the SQ109 peak area, together with very low levels $(<<1 \%$ of the SQ109 intensity) of $[+2 \mathrm{O}-2 \mathrm{H}]$ and $[+3 \mathrm{O}-2 \mathrm{H}]$, the $[+2 \mathrm{O}-2 \mathrm{H}]$ species appearing as a single peak, discussed more below.

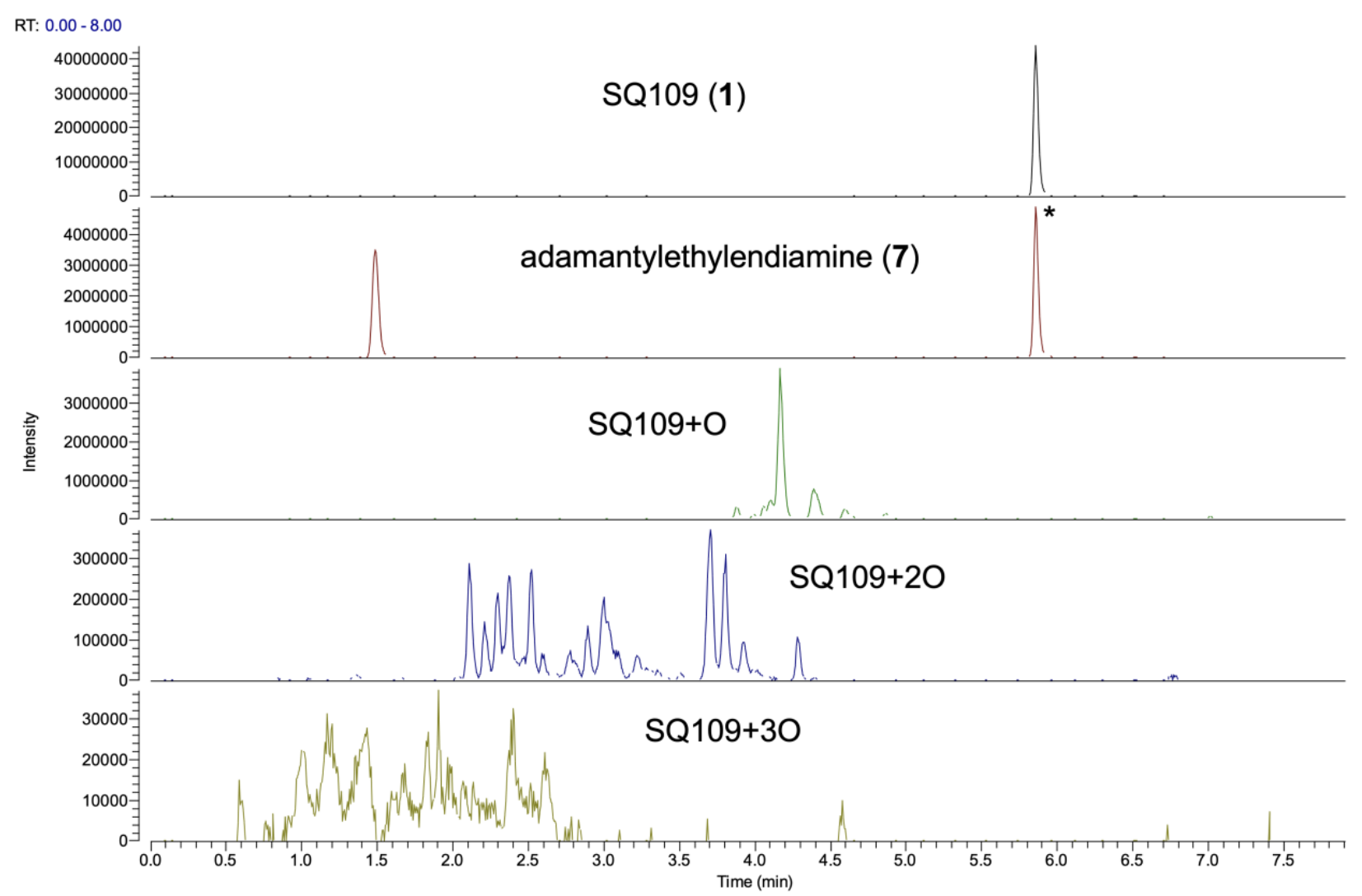

Figure 4. LC-MS data for lung extracts from M. tuberculosis infected Oryctolagus cuniculus dosed with SQ109 for 7 days. The asterisk represents is an in-source fragment of $\mathbf{7}$. 
Based then on these initial results, it appears that SQ109 is the major species in lung tissue, followed by several singly-oxygenated species and metabolite 7, although the latter might have a rather different ESI response.

In order to determine the actual amounts of 7 and the abundant $[+1 \mathrm{O}]$ compounds, as well as of other potential metabolites, we next investigated the following compounds as possible LC-MS quantification standards: the 7 compounds synthesized above - the 1-OH (9); 4-oxo (12); 7,9 epoxide (3); and the C1' (21), C5' (22), C6' (23) and C4' (24) adamantanol analogs of SQ109, together with geranial (13), geranic acid (14), geranial oxime (15a), the 2-isoxazolione 15b, N'adamantylethylenediamine (7), 2-adamantanone (19), adamantan-2-one oxime (16), 2aminoadamantane (18), geranylamine (17) and geranylethylenediamine (20). Compound 19 did not ionize and $\mathbf{3}$ was not observable when spiked into plasma, due presumably to covalent attachment to lysine residues in serum proteins, but the other compounds do serve as standards and these as well as 3 and 19 were also tested for antibacterial activity, as discussed below. Compound quantification results using these standards are shown in Table 1 together with LOQ (Limit of Quantification) results - the ability to detect a compound. 
Table 1. SQ109 and metabolite concentrations in M. tuberculosis infected rabbit lung tissue

\begin{tabular}{|c|c|c|c|c|c|c|}
\hline Compound & $\begin{array}{c}\text { Rabbit } 1 \\
(\mathrm{ng} / \mathrm{g})^{\mathrm{a}}\end{array}$ & $\begin{array}{c}\text { Rabbit } 2 \\
(\mathrm{ng} / \mathrm{g})^{\mathrm{a}}\end{array}$ & $\begin{array}{c}\text { Average } \\
(\mathbf{n g} / \mathbf{g})^{\mathbf{b}}\end{array}$ & $\begin{array}{c}\text { Average } \\
(\mu \mathbf{M})^{\mathbf{b}}\end{array}$ & $\begin{array}{c}\mathrm{LOQ}^{\mathrm{c}} \\
(\mathrm{ng} / \mathrm{mL})\end{array}$ & $\begin{array}{c}\mathbf{L O Q}^{\mathbf{c}} \\
(\mu \mathrm{M})\end{array}$ \\
\hline 1 (SQ-109) & $37000(4600)$ & $\begin{array}{c}45000 \\
(21000)\end{array}$ & 41000 & 124 & 100 & 0.30 \\
\hline 7 (adamantylethylenediamine) & $5500(360)$ & $7700(2200)$ & 6600 & 34 & 200 & 1.0 \\
\hline $9(1-\mathrm{OH})^{\mathrm{d}}$ & $\begin{array}{l}720 \\
(47)\end{array}$ & $850(190)$ & 785 & 2.3 & 10 & 0.03 \\
\hline 12 (4-oxo) & $\begin{array}{l}91 \\
(20)\end{array}$ & $220(110)$ & 156 & 0.45 & 100 & 0.29 \\
\hline 13 (geranial) & BLQ & BLQ & BLQ & BLQ & 20000 & 130 \\
\hline 14 (geranic acid) & BLQ & BLQ & BLQ & BLQ & 5000 & 30 \\
\hline 15a (geranyloxime) & BLQ & BLQ & BLQ & BLQ & 5000 & 30 \\
\hline 15b (2-isoxazoline) & BLQ & BLQ & BLQ & BLQ & 5000 & 30 \\
\hline 16 (2-adamantanone oxime) & BLQ & BLQ & BLQ & BLQ & 200 & 1.2 \\
\hline 17 (geranylamine) & BLQ & BLQ & BLQ & BLQ & 5000 & 33 \\
\hline 18 (2-adamantylamine) & $170(49)$ & $270(27)$ & 220 & 1.2 & 100 & 0.53 \\
\hline 20 (geranylethylenediamine) & $310(14)$ & $330(54)$ & 320 & 1.6 & 20 & 0.10 \\
\hline $21\left(1^{\prime}-\mathrm{OH}\right)$ & BLQ & BLQ & BLQ & BLQ & 50 & 0.14 \\
\hline $22\left(5^{\prime}-\mathrm{OH}\right)$ & $5600(870)$ & $\begin{array}{l}15000 \\
(5000)\end{array}$ & 10300 & 30 & 50 & 0.14 \\
\hline $23\left(6^{\prime}-\mathrm{OH}\right)$ & $1200(210)$ & $3500(1200)$ & 2350 & 6.8 & 50 & 0.14 \\
\hline $24\left(4^{\prime}-\mathrm{OH}\right)$ & $820(170)$ & $2100(680)$ & 1460 & 4.2 & 50 & 0.14 \\
\hline
\end{tabular}

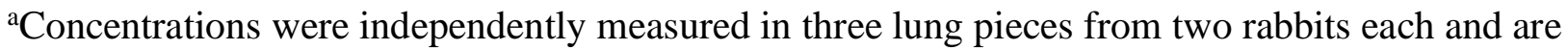
shown in ng compound/gram lung tissue. Standard deviations are shown in parentheses. ${ }^{\mathrm{b}}$ Average values for the 2 rabbits. LOQ results for lung tissue extracts. Values shown involved a 10x dilution in buffer. ${ }^{d}$ Peaks were not fully resolved from surrounding isomer metabolites and are likely inflated due to cross-talk. BLQ= Below the LOQ.

Based on these quantitative mass spectral results, it is clear that SQ109 is the major species found in lung tissue (Table 1) and is present at a $\sim 120 \mu \mathrm{M}$ level. This is an important result since SQ109 is known to potently inhibit $M$. tuberculosis growth in vitro with an $\mathrm{IC}_{50}$ of $\sim 0.52 \mu \mathrm{M}$. The major metabolites present, Table 1, based on retention times, exact masses and fragmentation patterns, were from two species: the 5'-OH analog of SQ109 (22) in which the tertiary C-H group is oxygenated to a C-OH group $(\mathrm{m} / \mathrm{z}=347)$, and the $\mathrm{N}^{\prime}$-adamantylethylenediamine $7(\mathrm{~m} / \mathrm{z}=195)$, both at $\sim 30 \mu \mathrm{M}$. Two other metabolites were also the result of adamantyl group hydroxylation, the 6 ' $-\mathrm{OH}$ at $\sim 7 \mu \mathrm{M}$ and the 4'-OH at $\sim 4 \mu \mathrm{M}$, Table 1. The C1'-OH analog 21 was not detected (indicated as BLQ, Below Level 
of Quantification) and based on LOQ data, Table 1, would be present at a $<0.1 \mu \mathrm{M}$ level, due presumably to steric hinderance in the P450 active site. On the other hand, the $\mathrm{C} 1-\mathrm{OH}$ analog $\mathbf{9}$, reported by Bukhdruker et al. ${ }^{22}$ to be formed by MtCYP124, was found, although again, at a low level $(\sim 2.3 \mu \mathrm{M})$.

In previous work ${ }^{16}$ it was proposed that $\mathrm{N}^{\prime}$-adamantylethylenediamine (the $\mathrm{m} / \mathrm{z}=195$ peak) arose due to oxidation of the C10 geranyl methylene group to form 10-hydroxy SQ109 (via the allylic radical that is stabilized by the adjacent $\mathrm{N}$ ), an unstable amino-alcohol that would be expected to immediately decompose to geranial and N-2-adamantylethylenediamine, Figure 3a, detected as the protonated $\mathrm{m} / \mathrm{z}$ $=195$ species. There are, however, what may appear at first sight to be several puzzles as to the more general origins of the "195" species. First, in their paper reporting the discovery of SQ10937, it was shown that in the ESI mass spectrum of pure SQ109, the $\mathrm{m} / \mathrm{z}=195.1$ peak had $\sim 80 \%$ of the intensity of the base peak, the molecular ion with $\mathrm{m} / \mathrm{z}=331.2$, meaning that at least in some ESI MS experiments, SQ109 can readily fragment to the N-2-adamantylethylenediamine species - even in the absence of a P450 cytochrome, raising the question as to the mechanism of this reaction, as well as its potential influence in determining metabolite concentrations. Second, Bukhdruker et al. ${ }^{22}$ reported a $\mathrm{m} / \mathrm{z}=195.2$ species from SQ109 in their MtCYP124 paper, although the fragmentation pattern they proposed generates $\mathrm{m} / \mathrm{z}=193$, the origins of the 2 additional Hs not being discussed. Third, as seen in the MS spectra shown in Figure 4, there is a large $\mathrm{m} / \mathrm{z}=195$ peak that has the same retention time as that of SQ109. The explanations for these results are first, that in ESI MS, the geranylamineprotonated-N species can undergo an "acyclic hydrogen rearrangement", as seen for example in thiamine ${ }^{38}$, and as illustrated in Figures $5 \mathrm{a}$ and $5 \mathrm{~b}$. This explains the origin of the $\mathrm{m} / \mathrm{z}=195$ peak 
a)<smiles>Cc1ncc2c(n1)Cc1sc(CCO)c(C)[n+]1CC2</smiles>

thiamine<smiles>C=C1C=NC(C)=NC1=N</smiles>

c)

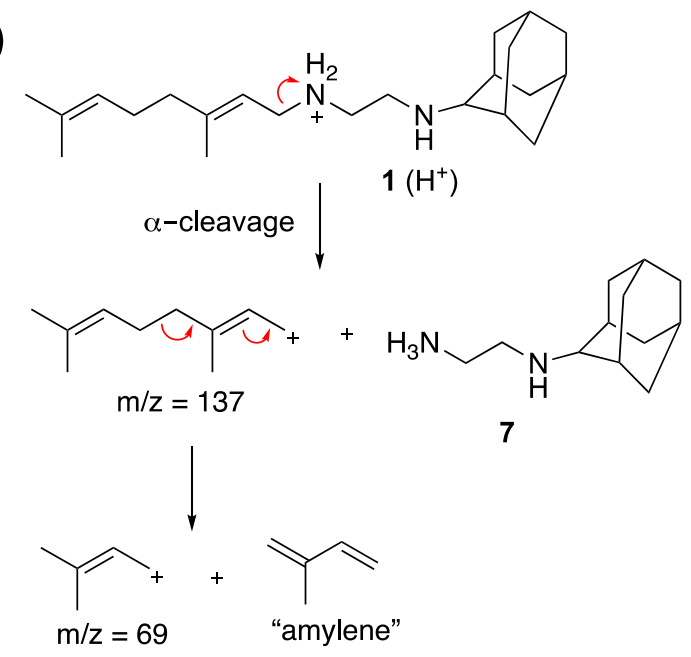

e)

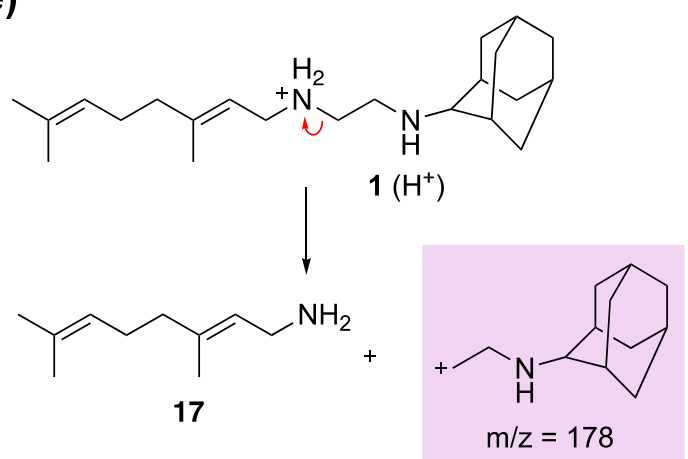

b)<smiles>CC(C)=CCCC1=CC[NH+]2CC[NH+]1CC2NCC1C2C=CC3CC(C2)CC1C3</smiles>

$1\left(\mathrm{H}^{+}\right)$<smiles>C=CC(=C)CCC=C(C)C</smiles>

d)<smiles>CC(C)=CCCC(C)=CC[NH2+]CCNC1CC2CC3C=C1CC3C2</smiles>

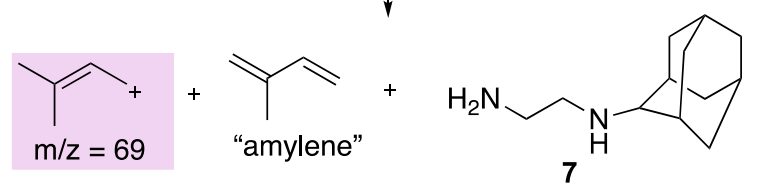

f)<smiles>[CH2+]CNC/C=C(\C=[18O])CCC=C(C)C</smiles><smiles>CC(C)=CCC/C(C)=C/CNCC[NH+]1CC2CC3CC(C2)CC1C3</smiles><smiles>CC(C)=CCC/C(C)=C/CNCCN</smiles>

$\mathrm{m} / \mathrm{z}=135$

Figure 5. "Acyclic hydrogen rearrangements" in thiamine and SQ109, together with alternate $\alpha$ cleavages in SQ109. a) Thiamine. The fragmentation of the thiamine cation to the thiazolium species is well known. b) Proposed fragmentation mechanism for the SQ109 cation to the Nadamantylethylenediamine $1^{\circ}$ ammonium species having $\mathrm{m} / \mathrm{z}=195(7)$, analogous to the hydrogen rearrangement seen with thiamine. c) $\alpha$-cleavage in SQ109 resulting in formation of a geranyl cation that then fragments to the dimethylallyl cation $(\mathrm{m} / \mathrm{z}=69)$ and the neutral amylene. $\mathrm{d})$ Concerted fragmentation of $\mathrm{m} / \mathrm{z}=331$ species to the dimethylallyl cation and the neutrals amylene (2methylbutene) and $\mathrm{N}$-adamantylethylenediamine. e) $\alpha$-cleavage fragmentation of the geranylamine (N11) protonated form of SQ109 also leads to formation on the $\mathrm{m} / \mathrm{z}=178$ species seen experimentally. f) $\alpha$-cleavage fragmentation of the adamantylamine-protonated form of SQ109 leads to the formation 
of the adamantyl cation with $\mathrm{m} / \mathrm{z}=135$ since this $2^{\circ}$ carbocation is more stable than the alternate $1^{\circ}$ carbocation with $\mathrm{m} / \mathrm{z}=180$. However, these peaks are extremely small or non-existent, indicating that the geranylamine nitrogen is far more basic.

in the absence of a cytochrome P450. Second, the identical retention time of the 195 peak (shown with an asterisk, on the right) with that of SQ109 is due to an "in-source" effect in which SQ109 fragments (as described above) between the atmospheric pressure ionization chamber and the mass spectrometer detector, and it is only the short-retention time species seen in Figure 4 that represents the actual N'adamantylethylenediamine metabolite, 7. This was confirmed by using authentic N'adamantylethylenediamine (7) as an LC-MS standard. 7 is indeed a very abundant SQ109 metabolite $(\sim 30 \mu \mathrm{M})$, as expected, due to formation of the allylic and nitrogen-stabilized radical formed at C-10 on hydrogen abstraction by a P450.

For the singly oxygenated species: stable oxygenation at the $\mathrm{C}^{\prime}$ ', $\mathrm{C} 4$ ', $\mathrm{C} 5^{\prime}$ ' and $\mathrm{C} 6$ ' positions of the adamantyl group as well as at each of the allylic $\left(\mathrm{Me}\right.$ as well as $\left.\mathrm{CH}_{2}\right)$ groups in the geranyl side-chain are theoretical possibilities and, as noted above, the order of reactivity is typically allyl $>3^{\circ}>2^{\circ}$. In addition, epoxidation and ketone formation are possible. The most abundant $(30 \mu \mathrm{M})$ singlyoxygenated metabolite is the adamantyl 5'-OH analog of SQ109 (there are 2 equivalent sites) in which the $3^{\circ} \mathrm{C}-\mathrm{H}$ group is converted (via a $3^{\circ}$ radical mechanism) to a $\mathrm{C}-\mathrm{OH}$ group, while the next most abundant metabolite is the (unique) 6'-OH adamantanol, again based on retention time, exact mass and fragmentation pattern, followed by the 4'-OH species $(4.2 \mu \mathrm{M})$. Since there are two $\mathrm{C}^{2}$ ' sites, one C6' site and four C4' sites, the amounts formed on a per-site basis are $15 \mu \mathrm{M}\left(\mathrm{C}^{\prime}\right.$ '), $6.8 \mu \mathrm{M}(\mathrm{C} 6$ ') and $\sim 1 \mu \mathrm{M}\left(\mathrm{C}^{\prime}\right.$ '), clearly reflecting the reactivity of the tertiary $\mathrm{C}^{\prime}$ ' site, as well as a decrease in susceptibility to oxygenation the closer a site is to the adamantylamine nitrogen, consistent with the observation that the $\mathrm{C} 1$ ' $-\mathrm{OH}$ species was not detectable. The $\mathrm{C} 5$ ' and $\mathrm{C} 6$ ' sites thus appear to be more "exposed" to the Fe in the P450 active site.

The mechanism for formation of $\mathrm{m} / \mathrm{z}=69$ species seen in many of the compounds investigated is also is of interest. These ions are very common in the fragmentation of isoprenoid species during EI (electron impact) ionization conditions but there, the parent ions are $\mathrm{M}^{+\cdot}$ and not $\mathrm{MH}^{+}$, the radical cation $\left(\mathrm{M}^{+\cdot}\right)$ fragmenting to the resonance-stabilized allyl cation and an allyl radical. In the ESI experiment, the parent is $\mathrm{MH}^{+}$and, in $\mathrm{SQ} 109$, in addition to the acyclic hydrogen rearrangement discussed above, Figure $7 \mathrm{~b}$, the geranyl ammonium species can undergo $\alpha$-cleavage to form the 
geranyl cation $\left(\mathrm{C}_{10} \mathrm{H}_{17} ; \mathrm{m} / \mathrm{z}=137.1325\right.$ observed $)$ and the neutral $\mathrm{N}$-adamantylethylenediamine. The geranyl cation then fragments to form the dimethylallyl cation $(\mathrm{m} / \mathrm{z}=69)$ and the neutral amylene $(2$ methylbutene), Figure 7c. It is also possible that there could be a concerted reaction, as shown in Figure $7 \mathrm{~d}$, leading to the same fragment.

These results are of mechanistic, enzyme inhibition interest since they indicate that it is primarily the geranyl nitrogen (N11) that is protonated in SQ109 and indeed, the alternate $\alpha$-cleavage mechanism shown in Figure $7 \mathrm{e}$ leads to the large $\mathrm{m} / \mathrm{z}=178$ species reported earlier ${ }^{23}$ in the ESI LC-MS of SQ109. On the other hand, protonation on the adamantyl nitrogen followed by $\alpha$-cleavage would result in $\mathrm{m} / \mathrm{z}$ $=180$ or 135 species and these are either very small or are not seen. These results strongly support the idea that it is protonation of the geranyl nitrogen which is key for MmpL3 inhibition activity since in the x-ray structure of MmpL3 (PDB ID code 6AJG), the geranyl nitrogen is only $2.45 \AA$ from the Asp$645 \mathrm{O} \delta 2$ atom, indicating a strong electrostatic interaction between the Asp and a protonated geranylamine nitrogen. They are also consistent with the previous obervation ${ }^{8}$ that of the two possible ethanolamine analogs of SQ109, the one that had the adamantyl NH converted to an O was more active against $M$. tuberculosis than was the other isomer.

What is also of interest about these results is that they seem to be inconsistent with the results of $\mathrm{pK}_{\mathrm{a}}$ calculations aimed at determining the site of protonation in SQ109. For example, using the Pipeline Pilot program from Accelrys ${ }^{39}$, Li et al. ${ }^{10}$ reported $\mathrm{pK}_{\mathrm{a}}$ values of 12.7 (adamantylamine NH) and 5.63 (geranylamine $\mathrm{NH}$ ), and using the Chemicalize program (https://chemicalize.com, developed by ChemAxon, http://www.chemaxon.com) we find $\mathrm{pK}_{\mathrm{a}}$ values of 10.2 (adamantylamine $\mathrm{NH}$ ) and 6.66 (geranylamine $\mathrm{NH}$ ). In both cases, the adamantylamine $\mathrm{NH}$ and not the geranylamine $\mathrm{NH}$ would be protonated. However, the $\mathrm{pK}_{\mathrm{a}}$ value(s) for SQ109 inside a lipid bilayer or inside a protein may be very different to those that would be found in aqueous solution or using standard computer programs. This is what is found with the tertiary amines in the lipid nanoparticles (LNPs) used in mRNA vaccines $^{40}$ where $\mathrm{pK}$ a values are shifted from $\sim 9.5$ (calculated) to $\sim 6.5$ (experiment) in the LNPs. It thus appears that SQ109 does not preferentially protonate on the adamantylamine NH.

As to the other metabolites, we found evidence for formation of the terminal oxygenated species 9 (at $\sim 2.3 \mu \mathrm{M}$ ) as well as the $\mathrm{C}-4$ oxo species, the ketone 12 (at $0.45 \mu \mathrm{M})$, Table 1 . There was no evidence for formation of the 7,9 epoxide $\mathbf{3}$, however, that is most likely due to the fact that we were unable to detect 3 when spiked into plasma. We also found evidence for formation of adamantylamine (18) and 
geranylethylenediamine (20) in the $1-2 \mu \mathrm{M}$ range, Table 1 , both of which are expected to form via hydroxylation adjacent the adamantylamine N1', Figures $5 \mathrm{~g}, \mathrm{~h}$.

With the more highly oxygenated species, it is clear that based on the initial mass spectral results, Figure 4, there are numerous di- and tri-oxygenated species present, but all are at low concentrations. Interestingly, the $\mathrm{m} / \mathrm{z}=361$ species appeared as a single peak, and based on exact mass measurements corresponds to a $[+2 \mathrm{O}-2 \mathrm{H}]$ analog of SQ109. This is the peak that was previously suggested ${ }^{16}$ to be an N-nitroso analog of SQ109, but the mass of that species is inconsistent with the nitrogen rule and our exact mass measurements. Since there are no $[+1 \mathrm{O}-2 \mathrm{H}] \mathrm{m} / \mathrm{z}=345$ peaks observed experimentallyas might be seen for example with a $\mathrm{CH}_{2}>\mathrm{CHOH}>\mathrm{CO}$ ketone or $\mathrm{CH}_{3}>\mathrm{CH}_{2} \mathrm{OH}>\mathrm{CHO}$ aldehyde reaction - it seems very likely that this compound must arise by a unique double-oxygenation plus a dehydrogenation, the obvious route being oxidation of the terminal Me to an aldehyde and thence (via the aldehyde diol) to the terminal carboxylic acid, with both the alcohol and aldehyde oxidations being predicted by using the SMART CYPs program (data not shown).

For the other highly oxygenated species: these can arise from very many combinations of reactions. For example, the $\mathrm{m} / \mathrm{z}=363$ is $[+2 \mathrm{O}]$ and this could arise from hydroxylation/epoxidation as well as direct ketone formation in the geranyl side-chain, together with adamantyl group hydroxylations $(\mathrm{C} 1$ ', C4', C5' and C6'). For 2 oxygens adding to the 11 predicted metabolically stable sites there are 55 possible $[+2 \mathrm{O}]$ species. The number of species can be calculated since they are "triangular numbers", that is, part of the series 1, 3, 6, 10, 15, 21, 28 etc. For example, 2 Os adding to 3 sites give 3 possible isomers; 2 Os adding to 4 sites give 6, etc. If hydroxylamines are included, that rises to 78 species, though in animals, the hydroxylamines would be expected to be further oxidized to nitrones and would then form oximes and amines. The $\mathrm{m} / \mathrm{z}=377$ is $[+3 \mathrm{O}-2 \mathrm{H}]$, and $379 \mathrm{is}[+3 \mathrm{O}]$, leading again to large numbers of possible compounds which are, however, all at very low $(<<1 \%)$ abundance, Figure 4 . No attempts to synthesize any such compounds was made, due to their low abundance and, as discussed below, their likely inactivity.

Antibacterial activity of SQ109 analogs and other possible metabolites. The question then arises: do any of the compounds detected above, or indeed, any of the proposed metabolites, have potent antibacterial activity? We thus next investigated the activity of 17 compounds-SQ109, 6 SQ109 analogs containing a single oxygen and the 10 potential metabolites that may form due to cleavage of unstable 
oxygenated species — against four bacteria: M. tuberculosis, M. smegmatis, B. subtilis and E. coli, organisms that are known to be inhibited by SQ109 ${ }^{8}$. Growth inhibition dose-response curves against M. tuberculosis are shown in Figure 6 and numerical values for all four bacteria are shown in Table 2 . The cyan bars in Figure 6 indicate the concentrations found in lung tissue (in $\mu \mathrm{M}$ units) and the pink bars indicate the LOQ values again in $\mu \mathrm{M}$ units.

As can be seen in Table 2 and Figure 6, there is - in most cases - little to no activity of any of the metabolites seen experimentally, or of other potential metabolites that might be formed, either by the host or the bacterium. We therefore conclude that it is unlikely that these compounds contribute to the observed activity of SQ109 against these or other bacteria.

For example, with SQ109 the concentration in lung tissue is $\sim 124 \mu \mathrm{M}$ (Table 1) and its $\mathrm{IC}_{50}$ against M. tuberculosis growth inhibition in vitro is $\sim 0.52 \mu \mathrm{M}$ (Table 2). Using the following dose-response Equation:

$\mathrm{I}(\%)=100(\%) \times \mathrm{C}(\mu \mathrm{M}) /\left[\mathrm{IC}_{50}(\mu \mathrm{M})+\mathrm{C}(\mu \mathrm{M})\right]$

where $\mathrm{I}(\%)$ is the percent growth inhibition and $\mathrm{C}$ is the drug or metabolite concentration, then there is $\sim 99.5 \%$ growth inhibition by SQ109. The only other metabolite that might appear to have activity against $M$. tuberculosis is 24 where $\mathrm{C}=4.2 \mu \mathrm{M}$ (Table 1) and $\mathrm{IC}_{50}=4.2 \mu \mathrm{M}$ also (Table 2) in which case $\mathrm{I}=50 \%$. However, since there will already be $99.5 \%$ growth inhibition from SQ109, any additional effect due to the presence of $\mathbf{2 4}$ will be insignificant. 

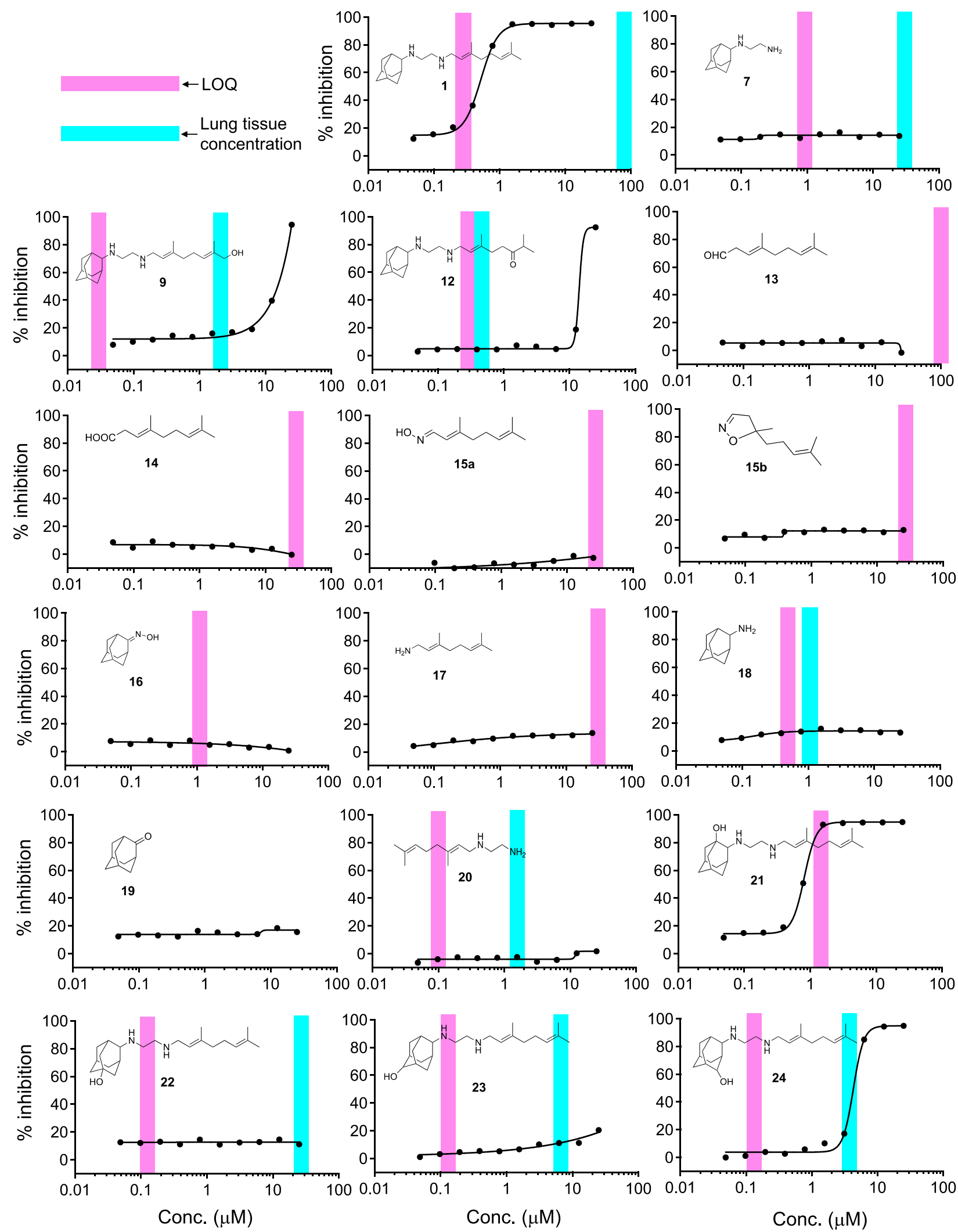

Figure 6. Dose-response curves for M. tuberculosis growth inhibition by SQ109 and some potential metabolites. 19 did not form a detectable ion in the ESI MS. Cyan bars=lung tissue concentration; pink bars=LOQ values. 
Table 2. Growth inhibitory concentrations of observed and putative SQ109 metabolites ${ }^{\mathrm{a}}$.

\begin{tabular}{|c|c|c|c|c|c|c|}
\hline $\begin{array}{c}\text { Compd. } \\
\text { No. }\end{array}$ & Structure & $\begin{array}{c}\mathrm{Ms} \\
\mathrm{IC}_{50}{ }^{(\mathrm{b})} \\
(\mu \mathrm{M})\end{array}$ & $\begin{array}{c}\text { Bs } \\
\text { IC }_{50}{ }^{(b)} \\
(\mu \mathrm{M})\end{array}$ & $\begin{array}{c}\mathrm{Ec} \\
\mathrm{IC}_{50}{ }^{(\mathrm{b})} \\
(\mu \mathrm{M})\end{array}$ & $\begin{array}{c}\text { Mtb } \\
\mathrm{IC}_{50}{ }^{(\mathrm{b})} \\
(\mu \mathrm{M})\end{array}$ & $\begin{array}{c}\text { Mtb } \\
\mathrm{IC}_{90}(\mathrm{c}) \\
(\mu \mathrm{M})\end{array}$ \\
\hline 1 & & 2.4 & 16 & 15 & 0.52 & 1.0 \\
\hline 7 & & $>500$ & $>500$ & $>500$ & $>25$ & $>25$ \\
\hline 9 & & 55 & $>500$ & 267 & 16 & 24 \\
\hline 12 & & 22 & 176 & 57 & 14 & 17 \\
\hline 13 & & $>500$ & $>500$ & $>500$ & $>25$ & $>25$ \\
\hline 14 & & $>500$ & $>500$ & $>500$ & $>25$ & $>25$ \\
\hline $15 \mathrm{a}$ & & $>500$ & $>500$ & $>500$ & $>25$ & $>25$ \\
\hline $15 b$ & & $>500$ & $>500$ & $>500$ & $>25$ & $>25$ \\
\hline 16 & & $>500$ & $>500$ & $>500$ & $>25$ & $>25$ \\
\hline 17 & & $>500$ & $>500$ & $>500$ & $>25$ & $>25$ \\
\hline 18 & & $>500$ & $>500$ & $>500$ & $>25$ & $>25$ \\
\hline 19 & & $>500$ & $>500$ & $>500$ & $>25$ & $>25$ \\
\hline 20 & & $>500$ & $>500$ & $>500$ & $>25$ & $>25$ \\
\hline 21 & & 14 & 54 & 118 & 0.81 & 1.3 \\
\hline
\end{tabular}


22

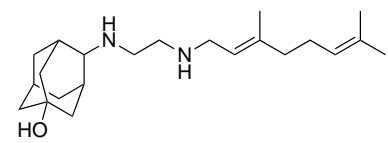

23

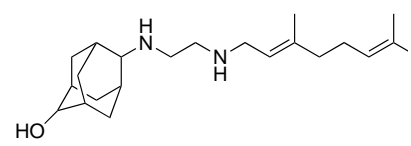

24

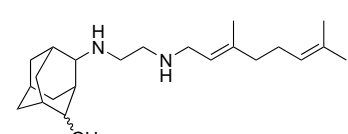

$\mathrm{OH}$
128

$>500$

184

166
$>25$

$>25$

25

6.2

${ }^{\mathrm{a}} \mathrm{Ms}=$ Mycobacterium smegmatis $; \mathrm{Bs}=$ Bacillus subtilis; $\mathrm{Ec}=$ Escherischia coli $; \mathrm{Mtb}=$ M. tuberculosis ${ }^{b} \mathrm{IC}_{50}=$ concentration that inhibits $50 \%$ of growth compared to no-drug control. ${ }^{\mathrm{C}} \mathrm{IC}_{90}=$ concentration that inhibits $90 \%$ of growth compared to no-drug control.

It is also important to consider whether any of the many possible di- or tri-oxygenated species that we did not synthesize might be expected to have extremely high activity. Based on the results discussed above, it is apparent that addition of just a single O atom to SQ109, in general, greatly reduces antibacterial activity. This is illustrated in Figures $7 \mathrm{a}$ and $7 \mathrm{~b}$ in which the decrease in compound activity against $M$. smegmatis and M. tuberculosis for each of the SQ109 analogs is indicated by a number (in red): the arrows indicate the site of oxygenation. For example, for the $\mathrm{C}^{\prime}$ '-OH compound 22 in M. smegmatis, there is a 90x increase in the $\mathrm{IC}_{50}$ value, from $2.4 \mu \mathrm{M}$ to $216 \mu \mathrm{M}$; for the terminal $1-\mathrm{OH} 9$, there is a $23 \mathrm{x}$ decrease in activity. For M. smegmatis, the average decrease in activity is $33 \mathrm{x}$ for the 6 SQ109 analogs, and for M. tuberculosis, the decreases in activity are again, in most cases, very (or unmeasurably) large. For $B$. subtilis and E. coli, the average decreases are $>15 \mathrm{x}$ and 8.6x, respectively. 
a)

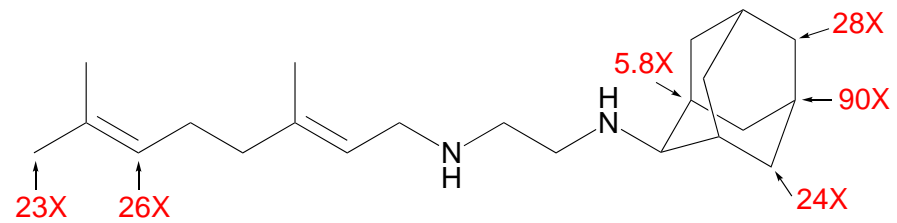

b)

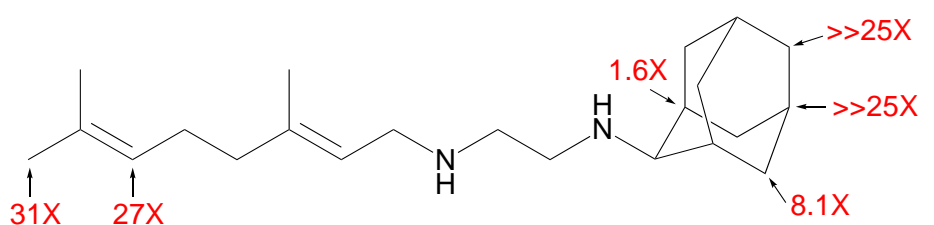

c)
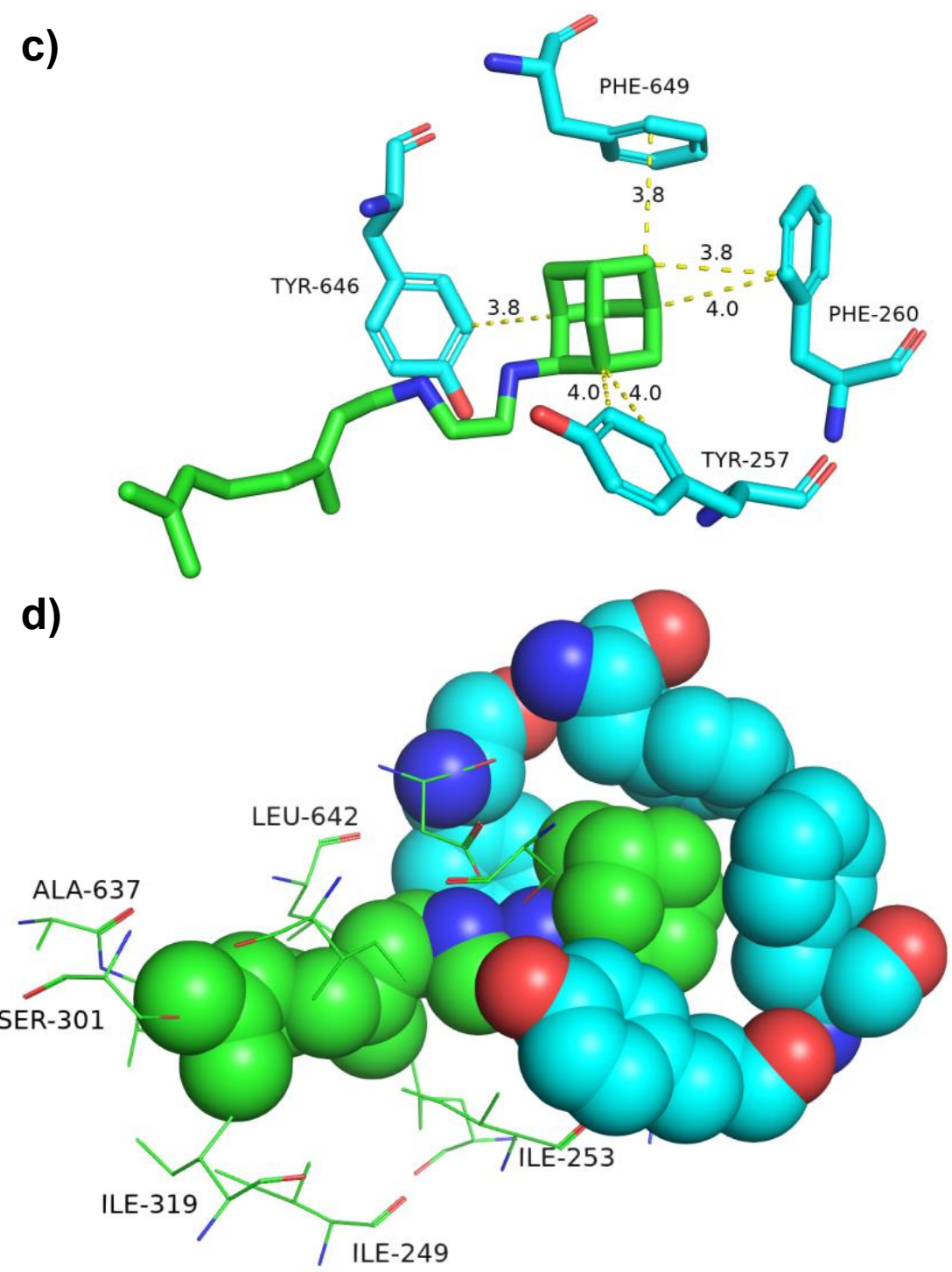

Figure 7. Effects of SQ109 oxygenation on cell activity and illustration of the hydrophobic pocket around the adamantane ring in SQ109 bound to MmpL3. a) Decrease in analog activity against $M$. smegmatis. b) Decrease in analog activity against $M$. tuberculosis. c) Stick diagram, distances are from $\mathrm{C} 5$ ' or $\mathrm{C} 6$ ' to the two conserved nearby Phe, and $\mathrm{Cl}^{\prime} / \mathrm{C}^{\prime}$ ' to nearby Tyr. d) Oxygenation of the adamantane at C4', C5' or C6' is very unfavorable for activity and may be due to repulsive van der Waals interactions with the two Phe residues that undergo very large conformational changes on SQ19 binding. 
A likely reason for the larger effects seen with M. smegmatis and M. tuberculosis is that MmpL3 is the major target and, based on the structure of SQ109 bound to MsMmpL3 (PDB ID code; 6AJG ${ }^{6}$ ) and as shown in Figures $7 \mathrm{c}$ and $7 \mathrm{~d}$, the adamantane ring is very close to the (conserved) phenyl groups, Phe-260 and Phe-649 (M. smegmatis sequence numbering). These two residues exhibit the largest conformational changes on binding of SQ109 to MsMmpL3 ${ }^{6}$ and are likely to be close to the OH groups in the SQ109 analogs, disrupting the hydrophobic interactions that would otherwise exist.

For the terminal, $\mathrm{C} 1-\mathrm{OH}$ species 9 and the C4-oxo species 12, there is a $\sim 26 \mathrm{x}$ decrease in activity on average against $M$. smegmatis and $M$. tuberculosis, again presumably due to unfavorable interactions with hydrophobic residues in the geranyl binding site, although clearly, measurement of the inhibition of MmpL3 activity as well crystal structures would be of interest to help determine all of the protein/ligand interactions. It is also possible that some oxygenated analogs simply do not get into the bacteria. That notwithstanding, if a single oxygenation greatly reduces anti-bacterial activity, then double and triple oxygenation is even less likely to produce a potent metabolite and in any case, the di- and tri-oxygenated species are all at very low levels.

\section{Conclusions}

The results we have discussed above are of broad general interest since it is known that the tuberculosis drug candidate SQ109 is also active against other pathogenic bacteria, yeasts and protozoa but is extensively metabolized in animals, presumably by cytochromes P450 in liver microsomes. Which structures actually form - and whether they have potent anti-infective activity - has been unknown. Here, we show that the major SQ109 metabolites are N'-adamantylethylenediamine 7 and the 5'adamantanol 22, both at $\sim 30 \mu \mathrm{M}$, together with small amounts of the 6'-adamantanol 23, the 4'adamantanol 24, and the 1-OH SQ109 analog 9, as well as trace levels of 4-oxo SQ109 12, adamantylamine $\mathbf{1 8}$ and geranylethylenediamine 19. These as well as 10 other potential metabolites have little or no activity against $M$. tuberculosis, M. smegmatis, B. subtilis and E. coli, bacteria that are inhibited by SQ1098 ${ }^{8}$ This lack of antibacterial activity strongly suggests that it is intact SQ109—and not a metabolite - that is required for therapeutic efficacy against TB, and also suggest that SQ109 and not a metabolite may be responsible for the activity seen against other bacteria, fungi and protozoa where "MmpL3-like" proteins have been reported ${ }^{41}$. 


\section{EXPERIMENTAL SECTION}

Chemical Synthesis and Characterization. Synthetic procedures and data for final compounds which were evaluated for biological activity is provided. Full synthesis details including the production of intermediates (designated as IM-1, IM-2, etc.) and schemes are given in the Supporting Information. All chemicals used were of reagent grade. Product formation was monitored by ${ }^{1} \mathrm{H}$ and ${ }^{13} \mathrm{C}$ NMR spectroscopy on Varian or Bruker spectrometers at 400 or $500 \mathrm{MHz}$ for ${ }^{1} \mathrm{H}$. Chemical shifts are reported in parts per million (ppm) from residual chloroform using the convention that low-field, highfrequency, paramagnetic or deshielded shifts are positive (IUPAC $\delta$-scale). Purity was determined by ${ }^{1} \mathrm{H}$ quantitative NMR (qNMR) at $500 \mathrm{MHz}$ using a Bruker Avance III HD NMR Spectrometer equipped with a BBFO CryoProbe, using Mnova software, as well as by using high-resolution mass spectrometry (HRMS).

\section{$N^{1-((1 r, 3 r, 5 r, 7 r)-a d a m a n t a n-2-y l)-N^{2}-((3-m e t h y l-3-(4-m e t h y l p e n t-3-e n-1-y l) o x i r a n-2-~}$ yl)methyl)ethane-1,2-diamine (3).}

To a solution of SQ109.2PTSA salt $(1.39 \mathrm{~g}, 2.06 \mathrm{mmol})$ in $90 \mathrm{~mL}$ DCM was added $m$-CPBA $(0.56 \mathrm{~g}$, $2.47 \mathrm{mmol}$ ) in three portions during four hours at $0{ }^{\circ} \mathrm{C}$ and the reaction mixture (RM) was stirred at the same temperature for $12 \mathrm{~h}$. The reaction was quenched with $18 \mathrm{~mL}$ of saturated aqueous $\mathrm{K}_{2} \mathrm{CO}_{3}$. The mixture was extracted with diethyl ether $(3 \times 30 \mathrm{~mL})$; the combined organic layers were dried over anhydrous $\mathrm{K}_{2} \mathrm{CO}_{3}$, filtered and concentrated in vacuo. The crude product was purified by silica gel flash chromatography using $\mathrm{NH}_{4} \mathrm{OH}: \mathrm{MeOH}: \mathrm{CHCl}_{3}$ (1:9:90) to afford 2,3-oxo-SQ109, 3 (45 mg, 6\%), 6,7-oxo-SQ109, 11 (15 mg, 2\%), 12 (48 mg, 7\%), and unreacted SQ109 (0.25 g, 38\%). Characterization data for $\mathbf{1 1}$ not provided, it was <70\% pure. 2,3-oxo-SQ109, $\mathrm{N}^{1}-((1 r, 3 r, 5 r, 7 r)$ adamantan-2-yl)-N²-((3-methyl-3-(4-methylpent-3-en-1-yl)oxiran-2-yl)methyl)ethane-1,2-diamine (3). ${ }^{1} \mathrm{H} \mathrm{NMR}\left(\mathrm{CDCl}_{3}, 500 \mathrm{MHz}\right): \delta 5.06(\mathrm{t}, J=7.5 \mathrm{~Hz}, 1 \mathrm{H}), 2.95-2.87(\mathrm{~m}, 7 \mathrm{H}), 2.72-2.68(\mathrm{~m}, 1 \mathrm{H})$, 2.08-1.97 (m, 6H), 1.88-1.83 (m, 5H), 1.71-1.69 (m, 5H), $1.66(\mathrm{~s}, 3 \mathrm{H}), 1.59(\mathrm{~s}, 3 \mathrm{H}), 1.55-1.54(\mathrm{~m}, 1 \mathrm{H})$, 1.48-1.42 (m, 1H), 1.26 (s, 3H). $\left.{ }^{13} \mathrm{C} \mathrm{NMR} \mathrm{(CDCl} 3,126 \mathrm{MHz}\right): \delta$ 132.1, 123.4, 62.4, 62.2, 60.7, 48.5, 45.6, 38.6, 37.5, 37.2 , 31.1, 27.4, 27.2, 25.3, 23.7, 17.7, 16.8. ESI HRMS: m/z [M+H] ${ }^{+}$calculated for $\mathrm{C}_{22} \mathrm{H}_{39} \mathrm{~N}_{2} \mathrm{O}^{+}$, 347.3057; found, 347.2987; purity = $86.4 \%$ (qNMR). 6,7-oxo-SQ109, [(E)-8-((2(((1r,3r,5r,7r)-adamantan-2-yl)amino)ethyl)amino)-2,6-dimethyloct-6-en-3-one $\quad$ (12). $\quad{ }^{1} \mathrm{H} \quad \mathrm{NMR}$ 
$\left(\mathrm{CDCl}_{3}, 400 \mathrm{MHz}\right): \delta 5.31(\mathrm{t}, J=5 \mathrm{~Hz}, 1 \mathrm{H}), 3.45(\mathrm{~d}, J=10 \mathrm{~Hz}, 2 \mathrm{H}), 3.09(\mathrm{~s}, 4 \mathrm{H}), 3.01(\mathrm{~s}, 1 \mathrm{H}), 2.63$ $2.57(\mathrm{~m}, 3 \mathrm{H}), 2.30(\mathrm{t}, J=7.5 \mathrm{~Hz}, 2 \mathrm{H}), 2.10-2.01(\mathrm{~m}, 4 \mathrm{H}), 1.92-1.88(\mathrm{~m}, 4 \mathrm{H}), 1.74-1.64(\mathrm{~m}, 9 \mathrm{H}), 1.10$ (s, 3H), $1.08(\mathrm{~s}, 3 \mathrm{H}) .{ }^{13} \mathrm{C} \mathrm{NMR}\left(\mathrm{CDCl}_{3}, 126 \mathrm{MHz}\right): \delta 213.9,141.7,117.9,62.3,45.3,44.9,43.3,40.9$, 38.3, 37.3, 37.1, 33.2, 31.0, 30.6, 27.2, 27.0, 18.3, 16.8. ESI HRMS: m/z $[\mathrm{M}+\mathrm{H}]^{+}$calculated for $\mathrm{C}_{22} \mathrm{H}_{39} \mathrm{~N}_{2} \mathrm{O}^{+}, 347.3057$; found, 347.3062; purity = 95.1\% (qNMR).

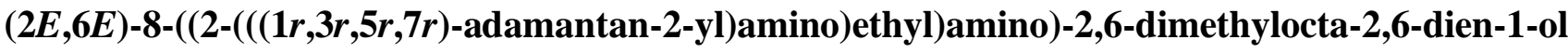
(9).

To a solution of $\mathrm{N}^{1}-\left((1 r, 3 r, 5 r, 7 r)\right.$-adamantan-2-yl)- $\mathrm{N}^{2}-((2 E, 6 E)-8-(($ tert-butyldimethylsilyl)oxy)-3,7dimethylocta-2,6-dien-1-yl)ethane-1,2-diamine $(0.17 \mathrm{~g}, 0.37 \mathrm{mmol})$ in $5 \mathrm{~mL}$ dry THF was added TBAF (1.14 mL, $1.14 \mathrm{mmol})$ and the RM was stirred at RT for $24 \mathrm{~h}$. The reaction was quenched with $5 \mathrm{~mL}$ of sat. aqueous $\mathrm{NaHCO}_{3}$ and extracted with $3 \times 15 \mathrm{~mL}$ EtOAc. The combined organic layers were dried over $\mathrm{Na}_{2} \mathrm{SO}_{4}$, filtered and concentrated in vacuo. The crude product was purified by silica gel flash chromatography using $\mathrm{NH}_{4} \mathrm{OH}: \mathrm{MeOH} \mathrm{CHCl}_{3}(2: 8: 90)$ to afford $\mathbf{9}(81 \mathrm{mg}, 64 \%)$ as an oil. ${ }^{1} \mathrm{H}$ NMR $\left(\mathrm{CDCl}_{3}, 500 \mathrm{MHz}\right): \delta 5.36-5.31(\mathrm{~m}, 2 \mathrm{H}), 3.97(\mathrm{~s}, 2 \mathrm{H}), 3.48(\mathrm{~d}, J=10 \mathrm{~Hz}, 2 \mathrm{H}), 3.07(\mathrm{~s}, 4 \mathrm{H})$, $2.94(\mathrm{~s}, 1 \mathrm{H}), 2.22-2.13(\mathrm{~m}, 4 \mathrm{H}), 2.04-2.01(\mathrm{~m}, 4 \mathrm{H}), 1.89-1.87(\mathrm{~m}, 4 \mathrm{H}), 1.73-1.69(\mathrm{~m}, 7 \mathrm{H}), 1.63-1.58$ $(\mathrm{m}, 5 \mathrm{H}) .{ }^{13} \mathrm{C} \mathrm{NMR}\left(\mathrm{CDCl}_{3}, 126 \mathrm{MHz}\right): \delta 142.2,135.7,124.0,118.0,68.0,62.5,45.6,45.3,43.5,39.0$, 37.5, 37.3, 31.0, 27.4, 27.2, 24.9, 16.3, 13.9. ESI HRMS: $\mathrm{m} / \mathrm{z}[\mathrm{M}+\mathrm{H}]^{+}$calculated for $\mathrm{C}_{22} \mathrm{H}_{39} \mathrm{~N}_{2} \mathrm{O}^{+}$, 347.3057; found, 347.3063; purity $=95.7 \%$ (qNMR).

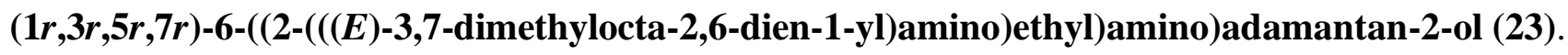

To a solution of $N$-((E)-3,7-dimethylocta-2,6-dien-1-yl)-2-(((1r,3r,5r,7r)-6-hydroxyadamantan-2yl)amino)acetamide $(0.21 \mathrm{~g}, 0.58 \mathrm{mmol})$ in $5 \mathrm{~mL} \mathrm{Et} 2 \mathrm{O}$ was added $\mathrm{LiAlH}_{4}(70 \mathrm{mg}, 1.86 \mathrm{mmol})$ and the RM was refluxed for $24 \mathrm{~h}$. The RM was cooled to room temperature and quenched by adding 0.5 $\mathrm{mL}$ of conc. $\mathrm{NH}_{4} \mathrm{OH}$, filtered and concentrated in vacuo. The crude product was purified by silica gel flash chromatography with $\mathrm{NH}_{4} \mathrm{OH}: \mathrm{MeOH} \mathrm{CHCl}_{3}(1: 9: 90)$ to afford $\mathbf{2 3}(65 \mathrm{mg}, 33 \%)$ as pale yellow color viscous oil. ${ }^{1} \mathrm{H}$ NMR $\left(\mathrm{CDCl}_{3}, 500 \mathrm{MHz}\right): \delta 5.27(\mathrm{t}, J=7.5 \mathrm{~Hz}, 1 \mathrm{H}), 5.08(\mathrm{t}, J=7.5 \mathrm{~Hz}, 1 \mathrm{H}), 3.81$ (s, 1H), $3.29(\mathrm{~d}, J=5.0 \mathrm{~Hz}, 2 \mathrm{H}), 2.77(\mathrm{~s}, 4 \mathrm{H}), 2.69(\mathrm{~s}, 1 \mathrm{H}), 2.19-2.00(\mathrm{~m}, 7 \mathrm{H}), 1.85-1.74(\mathrm{~m}, 8 \mathrm{H}), 1.67$ (s, 3H), 1.64 (s, 3H), 1.59 (s, 3H), 1.47-1.41 (m, 2H). $\left.{ }^{13} \mathrm{C} \mathrm{NMR} \mathrm{(CDCl} 3,126 \mathrm{MHz}\right): \delta$ 141.2, 131.9, $123.7,119.4,74.1,61.8,47.1,45.8,44.6,39.6,35.9,33.8,31.1,30.8,30.1,26.4,25.7,24.8,17.7,16.5$. 
ESI HRMS: $\mathrm{m} / \mathrm{z}[\mathrm{M}+\mathrm{H}]^{+}$calculated for $\mathrm{C}_{22} \mathrm{H}_{39} \mathrm{~N}_{2} \mathrm{O}^{+}$, 347.3057; found, 347.3062; purity $=95.5 \%$ (qNMR).

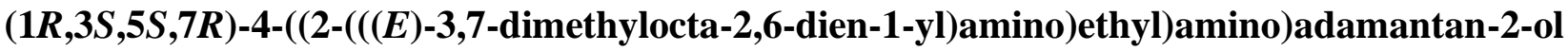

(24). To $4.5 \mathrm{~mL} 1 \mathrm{M} \mathrm{KOH}$ (10 equivalent) was added $4.5 \mathrm{~mL}$ of ethanolic solution of acetoxy ester, $(1 R, 3 S, 5 S, 7 R)-4-((2-(((E)-3,7-d i m e t h y l o c t a-2,6-d i e n-1-y l) a m i n o) e t h y l) a m i n o) a d a m a n t a n-2-y l$ acetate, $(0.17 \mathrm{~g}, 0.45 \mathrm{mmol})$. The reaction mixture was heated at $65^{\circ} \mathrm{C}$ for $12 \mathrm{~h}$. The $\mathrm{RM}$ was cooled to RT and extracted in $3 \times 20 \mathrm{~mL}$ of diethyl ether. The combined organic layers were dried on $\mathrm{Na}_{2} \mathrm{SO}_{4}$, filtered and concentrated in vacuo. The crude product was purified by silica gel flash chromatography with $\mathrm{NH}_{4} \mathrm{OH}: \mathrm{MeOH}: \mathrm{CHCl}_{3}(2: 8: 90)$ to afford $24(134 \mathrm{mg}, 87 \%)$ as an oil. ${ }^{1} \mathrm{H} \mathrm{NMR}\left(\mathrm{CDCl}_{3}, 500\right.$ $\mathrm{MHz}): \delta$ Mixture of equatorial and axial 4-OAc isomers (1:0.52) 5.29-5.25 (m, 1.9H), 5.33-5.29 (m, 1.5H) 5.09-5.06 (m, 1.5H), 4.24-4.23 (m, 0.5H), $3.44(\mathrm{~d}, \mathrm{~J}=10 \mathrm{~Hz}, 0.5 \times 2 \mathrm{H}), 3.38(\mathrm{~d}, \mathrm{~J}=5.0 \mathrm{~Hz}, 2 \mathrm{H})$ 2.93-2.85 (m, 7H), 2.71-2.70 (m, 1H), 2.09-1.97 (m, 11H), 1.88-1.77 (m, 9H), 1.72-1.64 (m, 15H), 1.51-1.39 (m, 3H). ${ }^{13} \mathrm{C} \mathrm{NMR}\left(\mathrm{CDCl}_{3}, 126 \mathrm{MHz}\right): \delta$ Mixture of equatorial and axial 4-OAc isomers (1:0.52) 141.3, 140.4, 131.8, 131.7, 123.9, 123.8, 120.0, 119.0, 73.8, 69.0, 63.8, 60.7, 47.8, 47.3, 46.1, $45.9,45.2,45.1,39.7,39.7,38.6,38.4,37.3,34.8,34.2,34.0,31.4,31.3,31.2,31.0,30.9,30.8,27.0$, 26.9, 26.4, 26.4, 25.7, 25.1, 17.7, 16.5, 16.4 ESI HRMS: $\mathrm{m} / \mathrm{z}[\mathrm{M}+\mathrm{H}]^{+}$calculated for $\mathrm{C}_{22} \mathrm{H}_{39} \mathrm{~N}_{2} \mathrm{O}^{+}$, 347.3057; found, 347.3055; purity $=95.8 \%$ (qNMR).

\section{Rabbit infection, treatment and tissue processing}

All animal studies were performed in Biosafety Level 3 (BSL3) facilities and approved by the Institutional Animal Care and Use Committee of Hackensack Meridian Health, NJ. All samples collected from $M$. tuberculosis infected animals were handled and processed in the BSL3 in compliance with protocols approved by the Institutional Biosafety Committee of Hackensack Meridian Health, NJ. Female New Zealand White (NZW) rabbits (Charles River Laboratories, Canada) were maintained under specific pathogen-free conditions and infected with $M$. tuberculosis HN878. At 16 weeks post infection, rabbits received seven oral daily doses of SQ109 at $25 \mathrm{mg} / \mathrm{kg}$. Twenty-four hours after the last dose, blood, lung tissue and lung granulomas (lesions) were collected and processed as previously described. ${ }^{42}$

All samples were stored at $-80^{\circ} \mathrm{C}$ until analyzed by LC/MS-MS. 


\section{LC-MS/MS Whole Tissue Analysis Method}

Neat $1 \mathrm{mg} / \mathrm{mL}$ DMSO stocks for SQ109 and metabolite standards were serial diluted in 50/50 ACN/Milli-Q water and subsequently diluted in drug free control tissue homogenates for creation of the standards and QCs. SQ109 standard was received from Sequella Inc. and metabolites were synthesized at the University of Illinois or were obtained commercially. Naïve New Zealand White (NZW) rabbit control lung was used to build standard curves. Control and study sample lung tissues were homogenized by adding 9 parts PBS buffer: 1 part tissue (a 10x dilution) and shaking the samples using a Fisher Bead Mill for 1 minute at 6000 RPM with zirconia beads. Standards, QCs, controls, and study samples were extracted by combining $20 \mu \mathrm{L}$ of study sample, QC, standard or control with $200 \mu \mathrm{L} \mathrm{50/50}$ acetonitrile/methanol containing $20 \mathrm{ng} / \mathrm{mL}$ of the internal standard (Verapamil). Extracts were vortexed for 5 minutes and centrifuged at 4000 RPM for 5 minutes. $100 \mu \mathrm{L}$ supernatant was transferred to a 96 well plate for HPLC-MS/MS analysis.

Quantitative LC-MS/MS analysis was performed on a Sciex Applied Biosystems Qtrap 6500+ triple-quadrupole mass spectrometer coupled to a Shimadzu Nexera X2 UHPLC system to quantify each analyte. Qualitative LC-MS analysis was performed on a Thermo Q-Exactive high-resolution mass spectrometer (QE-HRMS) at 70000 mass resolution using an Ultimate 3000 UHPLC system for chromatographic separation. Chromatography was performed on a Phenomenex Luna Omega Polar C18 HPLC column (2.1x100 mm; particle size, $3 \mu \mathrm{m})$ using a reverse phase gradient elution. Milli-Q deionized water with $0.1 \%$ formic acid was used for the aqueous mobile phase and $0.1 \%$ formic acid in acetonitrile for the organic mobile phase. Multiple-reaction monitoring (MRM) of precursor/fragment transitions in electrospray positive-ionization mode was used to quantify the analytes. Sample analysis was accepted if the concentrations of the quality control samples were within $20 \%$ of the nominal concentration. Data processing was performed using Analyst software (version

\subsection{2; Applied Biosystems Sciex).}

\section{B. subtilis growth inhibition assay.}

An overnight starter culture (in LB both) of B. subtilis was diluted 1000-fold (in fresh LB media) and grown to an $\mathrm{OD}_{600}$ of $\sim 0.3$ (approximately $3.5 \mathrm{~h}$ at $37^{\circ} \mathrm{C}$ ). This $\log$-phase culture was then diluted 500 -fold into fresh LB broth to generate the working solution. This working solution $(180 \mu \mathrm{L})$ was then transferred into every well in a flat-bottom 96-well plate except for the first column. Inhibitors were added at specific starting concentrations $(100 \mu \mathrm{M}-1 \mathrm{mM})$ with a total volume of $360 \mu \mathrm{L}$ (diluted 
with working solution) into the first column. The inhibitors were then sequentially diluted 2-fold across 12 wells. Plates were incubated at $37^{\circ} \mathrm{C}$ and shaken at $200 \mathrm{rpm}$ for $12 \mathrm{~h}$. The OD 600 values were then measured to determine $\mathrm{IC}_{50}$ values using GraphPad Prism software (version 7.04). Experiments were carried out in duplicate or triplicate. $\mathrm{IC}_{50}$ values were determined using a four-parameter variableslope function in the Prism program.

$\mathrm{Y}=$ Bottom $+\frac{(\text { Top }- \text { Bottom })}{1+10^{\left(\left(\log I C_{50}-\mathrm{X}\right) \times \text { Hill slope }\right)}}$

M. smegmatis growth inhibition assay. M. smegmatis (grown for 36-48 h) was diluted 1000-fold in fresh Middlebrook 7 H9 (plus 10\% ADC supplement, Sigma: M0553-1VL; 0.5\% glycerol; 0.05\% Tween 80$)$ media to generate a working solution. This working solution $(180 \mu \mathrm{L})$ was then transferred into every well in a flat-bottomed 96-well plate except for the second column and peripheral wells. Inhibitors were added at specific starting concentrations $(100 \mu \mathrm{M}-1 \mathrm{mM})$ with a total volume of 300 $\mu \mathrm{L}$ (diluted with working solution) to the second column. The inhibitors were then sequentially diluted 3 -fold across 10 wells; $200 \mu \mathrm{L}$ of water was added to each peripheral well to prevent water evaporation from the plate. Plates were incubated at $37^{\circ} \mathrm{C}$, with shaking at $200 \mathrm{rpm}$ for $48 \mathrm{~h}$. The $\mathrm{OD}_{600}$ values were then measured to determine bacterial growth inhibition, as described above.

E. coli growth-inhibition assay. An overnight starter culture of E. coli (K12) was diluted 1000-fold and grown to an $\mathrm{OD}_{600}$ value of $\sim 0.3$. These log-phase cultures were then diluted 500 -fold into fresh LB broth to generate a working solution. Working solution $(200 \mu \mathrm{L})$ was transferred into each well of a 96-well culture plate. Inhibitors were then added at $1 \mathrm{mM}$ and sequentially diluted 3-fold to $46 \mathrm{nM}$, keeping the volume and culture broth composition constant. Plates were incubated for $12 \mathrm{~h}$ at $37{ }^{\circ} \mathrm{C}$ with shaking at $200 \mathrm{rpm}$. The $\mathrm{OD}_{600}$ values were then measured to determine bacterial growth inhibition, as described above.

M. tuberculosis growth inhibition assay. Compounds were dissolved in DMSO at $10 \mathrm{mM}$. For each compound, a ten-point two-fold dilution series was dispensed onto 96-well plates using a Tecan D300e Digital Dispenser to achieve the final incubation concentration range of 0.04883 to $25 \mu \mathrm{M}$. $M$. tuberculosis $\mathrm{H} 37 \mathrm{Rv}$ was grown in Middlebrook 7H9 medium (10\% ADC, 0.2\% glycerol, $0.05 \%$ Tween 80 ) to a mid-log optical density $\left(\mathrm{OD}_{600}\right)$ of 0.4 and diluted to $\mathrm{OD}_{600}=0.03$. $200 \mu \mathrm{L}$ of adjusted culture were added per well. SQ109 (compound 1) was used as a positive control. Untreated control wells containing 1\% DMSO were included on each plate. Two biological replicates were performed for each 
compound. Plates were incubated at $37^{\circ} \mathrm{C}$ with shaking $(110 \mathrm{rpm})$ for 5 days. On day 5 , wells were then resuspended manually and the OD600 was read with a Tecan Infinite M200 plate reader. Data is expressed as percent growth inhibition and curves were fit by using GraphPad Prism software using nonlinear regression (variable slope, four parameters).

\section{ASSOCIATED CONTENT}

\section{Supporting Information.}

Supporting Information is available free of charge at http://pubs.acs.org.

Materials and Methods, Table S1, Figures S1-S5

\section{Author Information}

\section{Corresponding Authors}

Eric Oldfield - Department of Chemistry, University of Illinois at Urbana-Champaign, Urbana, IL 61801, USA; http://orcid.org/0000-0002-0996-7352; Email: eoldfiel@illinois.edu

Satish R. Malwal - Department of Chemistry, University of Illinois at Urbana-Champaign, Urbana, IL 61801, USA; http://orcid.org/0000-0001-7606-1932; Email: satishm@illinois.edu

\section{Authors}

Matthew D. Zimmerman - Center for Discovery and Innovation, 111 Ideation Way, Nutley, NJ 07110, United States; http://orcid.org/0000-0002-4390-3555

Nadine Alvarez - Center for Discovery and Innovation, 111 Ideation Way, Nutley, NJ 07110, United States; https://orcid.org/0000-0002-9045-5740

Jansy P. Sarathy - Center for Discovery and Innovation, 111 Ideation Way, Nutley, NJ 07110, United States; https://orcid.org/0000-0002-1532-146X 
Véronique Dartois - Center for Discovery and Innovation, 111 Ideation Way, Nutley, NJ 07110,

United States; Hackensack School of Medicine, Department of Medical Sciences, 123, Metro

Boulevard, Nutley, NJ 07110, United States; https://orcid.org/0000-0001-9470-5009

Carol A. Nacy - Sequella, Inc., 9610 Medical Center Drive, Suite 200, Rockville, MD 20850, United States; https://orcid.org/0000-0001-9546-3785

\section{Notes}

The authors declare no competing financial interests.

\section{Acknowledgements}

This work was supported by the University of Illinois Foundation, a Harriet A. Harlin Professorship (to E.O) and the United States Public Health Service (National Institutes of Health grant S10OD023524 to V.D.)

\section{References.}

1. World Health Organization. Global Tuberculosis Report 2019; World Health Organization: Geneva, Switzerland, 2019.

2. Migliori, G. B.; Tiberi, S.; Zumla, A.; Petersen, E.; Chakaya, J. M.; Wejse, C.; Muñoz Torrico, M.; Duarte, R.; Alffenaar, J. W.; Schaaf, H. S.; Marais, B. J.; Cirillo, D. M.; Alagna, R.; Rendon, A.; Pontali, E.; Piubello, A.; Figueroa, J.; Ferlazzo, G.; García-Basteiro, A.; Centis, R.; Visca, D.; D'Ambrosio, L.; Sotgiu, G., MDR/XDR-TB management of patients and contacts: Challenges facing the new decade. The 2020 clinical update by the Global Tuberculosis Network. Int. J. Infect. Dis. 2020, 92S, S15-S25.

3. Protopopova, M.; Hanrahan, C.; Nikonenko, B.; Samala, R.; Chen, P.; Gearhart, J.; Einck, L.; Nacy, C. A., Identification of a new antitubercular drug candidate, SQ109, from a combinatorial library of 1,2-ethylenediamines. J. Antimicrob. Chemother. 2005, 56, 968-974.

4. Sacksteder, K. A.; Protopopova, M.; Barry, C. E., 3rd; Andries, K.; Nacy, C. A., Discovery and development of SQ109: a new antitubercular drug with a novel mechanism of action. Future Microbiol. 
2012, 7, 823-837.

5. Tahlan, K.; Wilson, R.; Kastrinsky, D. B.; Arora, K.; Nair, V.; Fischer, E.; Barnes, S. W.; Walker, J. R.; Alland, D.; Barry, C. E., 3rd; Boshoff, H. I., SQ109 targets MmpL3, a membrane transporter of trehalose monomycolate involved in mycolic acid donation to the cell wall core of Mycobacterium tuberculosis. Antimicrob. Agents Chemother. 2012, 56, 1797-1809.

6. Zhang, B.; Li, J.; Yang, X.; Wu, L.; Zhang, J.; Yang, Y.; Zhao, Y.; Zhang, L.; Yang, X.; Yang, X.; Cheng, X.; Liu, Z.; Jiang, B.; Jiang, H.; Guddat, L. W.; Yang, H.; Rao, Z., Crystal structures of membrane transporter MmpL3, an Anti-TB Drug Target. Cell 2019, 176, 636-648.

7. Su, C. C.; Klenotic, P. A.; Bolla, J. R.; Purdy, G. E.; Robinson, C. V.; Yu, E. W., MmpL3 is a lipid transporter that binds trehalose monomycolate and phosphatidylethanolamine. Proc Natl Acad Sci U S A 2019, 116, 11241-11246.

8. Li, K.; Schurig-Briccio, L. A.; Feng, X.; Upadhyay, A.; Pujari, V.; Lechartier, B.; Fontes, F. L.; Yang, H.; Rao, G.; Zhu, W.; Gulati, A.; No, J. H.; Cintra, G.; Bogue, S.; Liu, Y. L.; Molohon, K.; Orlean, P.; Mitchell, D. A.; Freitas-Junior, L.; Ren, F.; Sun, H.; Jiang, T.; Li, Y.; Guo, R. T.; Cole, S. T.; Gennis, R. B.; Crick, D. C.; Oldfield, E., Multitarget drug discovery for tuberculosis and other infectious diseases. J. Med. Chem. 2014, 57, 3126-3139.

9. Feng, X.; Zhu, W.; Schurig-Briccio, L. A.; Lindert, S.; Shoen, C.; Hitchings, R.; Li, J.; Wang, Y.; Baig, N.; Zhou, T.; Kim, B. K.; Crick, D. C.; Cynamon, M.; McCammon, J. A.; Gennis, R. B.; Oldfield, E., Antiinfectives targeting enzymes and the proton motive force. Proc Natl Acad Sci U S A 2015, 112, E7073-E7082.

10. Li, W.; Upadhyay, A.; Fontes, F. L.; North, E. J.; Wang, Y.; Crans, D. C.; Grzegorzewicz, A. E.; Jones, V.; Franzblau, S. G.; Lee, R. E.; Crick, D. C.; Jackson, M., Novel insights into the mechanism of inhibition of MmpL3, a target of multiple pharmacophores in Mycobacterium tuberculosis. Antimicrob Agents Chemother 2014, 58, 6413-6423.

11. Veiga-Santos, P.; Li, K.; Lameira, L.; de Carvalho, T. M.; Huang, G.; Galizzi, M.; Shang, N.; Li, Q.; Gonzalez-Pacanowska, D.; Hernandez-Rodriguez, V.; Benaim, G.; Guo, R. T.; Urbina, J. A.; Docampo, R.; de Souza, W.; Oldfield, E., SQ109, a new drug lead for Chagas disease. Antimicrob Agents Chemother 2015, 59, 1950-1961.

12. Li, K.; Wang, Y.; Yang, G.; Byun, S.; Rao, G.; Shoen, C.; Yang, H.; Gulati, A.; Crick, D. C.; Cynamon, M.; Huang, G.; Docampo, R.; No, J. H.; Oldfield, E., Oxa, thia, heterocycle, and carborane 
analogues of sq109: bacterial and protozoal cell growth inhibitors. ACS Infect Dis 2015, 1, 215-221. 13. Gil, Z.; Martinez-Sotillo, N.; Pinto-Martinez, A.; Mejias, F.; Martinez, J. C.; Galindo, I.; Oldfield, E.; Benaim, G., SQ109 inhibits proliferation of Leishmania donovani by disruption of intracellular $\mathrm{Ca}(2+)$ homeostasis, collapsing the mitochondrial electrochemical potential $(\Delta \Psi(\mathrm{m}))$ and affecting acidocalcisomes. Parasitol. Res. 2020, 119, 649-657.

14. García-García, V.; Oldfield, E.; Benaim, G., Inhibition of Leishmania mexicana growth by the tuberculosis drug SQ109. Antimicrob. Agents Chemother. 2016, 60, 6386-6389.

15. Jia, L.; Tomaszewski, J. E.; Hanrahan, C.; Coward, L.; Noker, P.; Gorman, G.; Nikonenko, B.; Protopopova, M., Pharmacodynamics and pharmacokinetics of SQ109, a new diamine-based antitubercular drug. Br. J. Pharmacol. 2005, 144, 80-87.

16. Jia, L.; Noker, P. E.; Coward, L.; Gorman, G. S.; Protopopova, M.; Tomaszewski, J. E., Interspecies pharmacokinetics and in vitro metabolism of SQ109. Br. J. Pharmacol. 2006, 147, 476485.

17. Chen, P.; Gearhart, J.; Protopopova, M.; Einck, L.; Nacy, C. A., Synergistic interactions of SQ109, a new ethylene diamine, with front-line antitubercular drugs in vitro. J. Antimicrob. Chemother. 2006, 58, 332-337.

18. Unissa, A. N.; Subbian, S.; Hanna, L. E.; Selvakumar, N., Overview on mechanisms of isoniazid action and resistance in Mycobacterium tuberculosis. Infect. Genet. Evol. 2016, 45, 474-492.

19. Gopal, P.; Sarathy, J. P.; Yee, M.; Ragunathan, P.; Shin, J.; Bhushan, S.; Zhu, J.; Akopian, T.; Kandror, O.; Lim, T. K.; Gengenbacher, M.; Lin, Q.; Rubin, E. J.; Grüber, G.; Dick, T., Pyrazinamide triggers degradation of its target aspartate decarboxylase. Nat. Commun. 2020, 11, 1661.

20. Nebert, D. W.; Wikvall, K.; Miller, W. L., Human cytochromes P450 in health and disease. Philos. Trans. R Soc. Lond B. Biol. Sci. 2013, 368, 20120431.

21. Ortiz de Montellano, P. R., Potential drug targets in the Mycobacterium tuberculosis cytochrome P450 system. J. Inorg. Biochem. 2018, 180, 235-245.

22. Bukhdruker, S.; Varaksa, T.; Grabovec, I.; Marin, E.; Shabunya, P.; Kadukova, M.; Grudinin, S.; Kavaleuski, A.; Gusach, A.; Gilep, A.; Borshchevskiy, V.; Strushkevich, N., Hydroxylation of antitubercular drug candidate, sq109, by mycobacterial cytochrome P450. Int. J. Mol. Sci. 2020, 21, 7683.

23. Johnston, J. B.; Kells, P. M.; Podust, L. M.; Ortiz de Montellano, P. R., Biochemical and structural 
characterization of CYP124: a methyl-branched lipid omega-hydroxylase from Mycobacterium tuberculosis. Proc. Natl. Acad. Sci. U. S. A. 2009, 106, 20687-20692.

24. Evangelista, E. A.; Kaspera, R.; Mokadam, N. A.; Jones, J. P., 3rd; Totah, R. A., Activity, inhibition, and induction of cytochrome P450 2J2 in adult human primary cardiomyocytes. Drug Metab. Dispos. 2013, 41, 2087-2094.

25. Guengerich, F. P., Mechanisms of Cytochrome P450-Catalyzed Oxidations. ACS Catal. 2018, 8, 10964-10976.

26. Ashenhurst, J. 3 Factors That Stabilize Free Radicals. https://www.masterorganicchemistry.com/2013/08/02/3-factors-that-stabilize-free-radicals/ 2020.

27. Hou, X.; Zhou, J.; Yu, S.; Zhou, L.; Zhang, Y.; Zhong, D.; Chen, X., Differences in the in vivo and in vitro metabolism of imrecoxib in humans: formation of the rate-limiting aldehyde intermediate. Drug Metab. Dispos. 2018, 46, 1320-1328.

28. de Bruyn Kops, C.; Stork, C.; Š́́cho, M.; Kochev, N.; Svozil, D.; Jeliazkova, N.; Kirchmair, J., GLORY: generator of the structures of likely cytochrome p450 metabolites based on predicted sites of metabolism. Front. Chem. 2019, 7, 402.

29. Matlock, M. K.; Hughes, T. B.; Swamidass, S. J., XenoSite server: a web-available site of metabolism prediction tool. Bioinformatics 2015, 31, 1136-7113.

30. Olsen, L.; Montefiori, M.; Tran, K. P.; Jørgensen, F. S., SMARTCyp 3.0: enhanced cytochrome P450 site-of-metabolism prediction server. Bioinformatics 2019, 35, 3174-3175.

31. Chacón-García, L.; Valle-Sánchez, M.; Contreras-Celedón, C. A., A Novel Semisynthetic Anion Receptor: Synthesis and Ion Recognition of (1-H-pyrrol-2-yl)-4-oxo-perezone. Lett. Org. Chem. 2013, $10,632-636$.

32. Bruch, M.; Jun, Y. M.; Luedtke, A. E.; Schneider, M.; Timberlake, J. W., Synthesis of tetraisopropylethane and tetracyclopropylethane, and generation of the pentacyclopropylethyl carbocation. J. Org. Chem. 1986, 51, 2969-2973.

33. Paraja, M.; Matile, S., Primary anion- $\pi$ catalysis of epoxide-opening ether cyclization into rings of different sizes: access to new reactivity. Angew Chem. Int. Ed. Engl. 2020, 59, 6273-6277.

34. Barbara, J. E.; Kazmi, F.; Parkinson, A.; Buckley, D. B., Metabolism-dependent inhibition of CYP3A4 by lapatinib: evidence for formation of a metabolic intermediate complex with a nitroso/oxime metabolite formed via a nitrone intermediate. Drug Metab. Dispos. 2013, 41, 1012- 
1022.

35. Meng, Q.; Luo, H.; Chen, Y.; Wang, T.; Yao, Q., Synthesis of novel [1,2]-diamines with antituberculosis activity. Bioorg. Med. Chem. Lett. 2009, 19, 5372-5375.

36. Henkel, J. G.; Spector, J. H., Studies in the 2,4-disubstituted adamantanes. Preparation and reactivity of pure epimeric 4-hydroxy- and 4-methoxyadamantan-2-ones. J. Org. Chem. 1983, 48, $3657-3661$.

37. Lee, R. E.; Protopopova, M.; Crooks, E.; Slayden, R. A.; Terrot, M.; Barry, C. E., 3rd, Combinatorial lead optimization of [1,2]-diamines based on ethambutol as potential antituberculosis preclinical candidates. J. Comb. Chem. 2003, 5, 172-187.

38. Steckel, A.; Schlosser, G., An organic chemist's guide to electrospray mass spectrometric structure elucidation. Molecules 2019, 24, 611.

39. BIOVIA Pipeline Pilot, https://www.3ds.com/products-services/biovia/products/datascience/pipeline-pilot/chemistry/.

40. Buschmann, M. D.; Carrasco, M. J.; Alishetty, S.; Paige, M.; Alameh, M. G.; Weissman, D., Nanomaterial Delivery Systems for mRNA Vaccines. Vaccines 2021, 9, 65.

41. Malwal S. R.; Baek K. H.; Phan T. N.; Lee H.; Li, Z. H.; Moreno, S. N; No, J. H.; Oldfield, E. Lipid Transporters: From Bacteria, Protozoa, Fungi and Plants, to Mice and Men. 2021, 10.26434/chemrxiv.14538267.v1

42. Blanc, L.; Sarathy, J. P.; Alvarez Cabrera, N.; O'Brien, P.; Dias-Freedman, I.; Mina, M.; Sacchettini, J.; Savic, R. M.; Gengenbacher, M.; Podell, B. K.; Prideaux, B.; Ioerger, T.; Dick, T.; Dartois, V., Impact of immunopathology on the antituberculous activity of pyrazinamide. J. Exp. Med. 2018, 215, 1975-1986. 
$\longrightarrow \mathrm{N}_{\mathrm{H}}$

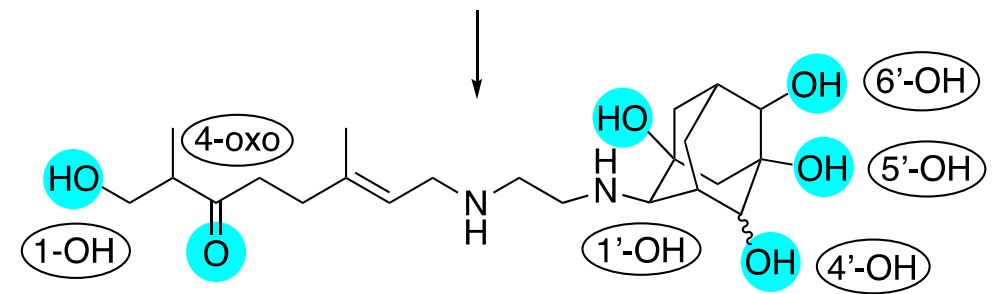

